\title{
التوافق بين مخرجات التعليم ومتطلبات سوق العمل لتعزيز قدرات الطاقات البشرية في عصر الأتمتة
}

د. عادل عبد العزيز السن

مستشار المنظمة العربية للتنمية الإدارية جامعة الدول العربية 


\section{Abstract:-}

\section{Compatibility between educational outcomes and labor market requirements}

\section{To enhance the capabilities of the human potential in the era of automation}

The economies of Arab countries face a major challenge as a result of the human race in Arab countries still suffering from a large knowledge, skill and technical gap between the education and training they received and the labor market needs, although this gap differs in size and effects from one country to another.

The world is also witnessing a major turning point towards automation (the second machine age) where the technical limits of the activities that machines can perform better than humans are rapidly expanding, especially in the era of artificial intelligence, humanlike robots and quantum computing. Significant employment from the labor market

The research aims to shed light on the dimensions of the knowledge, skill and technology gap for university graduates, and to identify the reasons for the mismatch between educational outcomes and labor market requirements, and the challenges that graduates face in the labor market in Arab countries.

The research concluded with presenting some strategies, initiatives and programs that would enhance the knowledge economy system and develop the relationship between educational outputs and labor market needs. And the role of governments, the private sector, institutions and Arab financing funds in this regard, in line with the requirements of the automation era, which will greatly affect the future of some jobs.

\section{key words:}

1- Automation is to make the procedures and machines run and operate automatically. It is also called "automation," meaning the use of technologies that require a minimal amount of human intervention, in various industrial, commercial and service sectors in order to ensure the smooth and accurate flow of procedures and business automatically and with the least possible error. The definition of automation includes "robotics" and artificial intelligence.

2- Intermediate jobs: These are jobs that involve significant levels of interaction between humans and machines in various fields

3- The labor market: It is the field of job supply and demand, and it is a type of economic market in which there are job seekers, job offers and agencies that form a link between those who offer certain jobs and those who seek these jobs 
مقدمة:

تواجه اقتصاديات الدول العربية تحدياً كبيراً نتيجة سوء استخدام الموارد البشرية والمادية، وعدم القدرة على ترتيب الأولويات في استغلال الموارد المتاحة سواء البشرية أو المادية وتوزيعها على الاستخدامات المتنافسة بما يحقق بناء اقتصاد فعّال وقوي.

وعلى الرغم من أهمية الطاقات البشرية المؤهلة في بناء اقتصاديات الدول ونجاح خطط التنمية الاقتصادية والاجتماعية، إلا أن العنصر البشري في الدول العربية لازال يعاني من وجود فجوة معرفية ومهارية وتقنية كبيرة بين ما تلقاه من تعليم وتدريب وبين احتياجات سوق العمل، وإن كانت هذه الفجوة تختلف في حجمها وتأثيراتها من دولة إلى أخرى. كذلك يشـهد العالم نقطة تحول رئيسية نحو الأتمتة (عصـر الآلة الثاني) حيث تشهـ الحدود

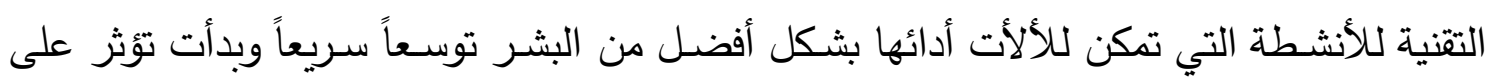
جميع أماكن العمل، فإذا كانت المهام التي تمت أتمتتها منذ أعوام قليلة بواســـة الروبوتات وأجهزة الحاسـوب تعتبر بسـيطة وروتينية، فإن الفترة الحالية في عصـر الذكاء الاصــطناعي والروبوتات الثـبيهة بالبشـر والحوسـبة الكمية أدت إلى تطور التكنولوجيا بسـرعة كبيرة لتأدية المهام المتكررة البسيطة، إضافة إلى الأنشطة الأكثر تعقيداً التي تتطلب مهام معرفية. ولذلك يعتبر التعليم والتدريب، مصــدر الزيادة الرئيســـة في إنتاجية الأيدي العاملة ودخلها، ويشـكلان مع البيئة الملائمة، الأسـلوب المباشـر لمعادلة الفرص بين مجموعات الدخل المختلفة، فكلما زادت المنافسـة العالمية بين المنتجين تركز معيار النجاح حول تراكم المهارات المهنية القابلة

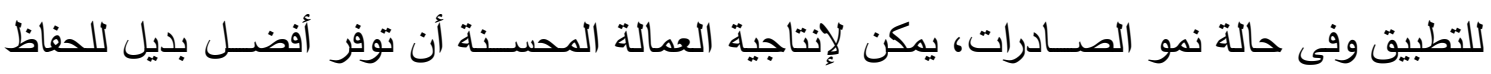
على القدرة على التتافس وذلك من خلال التعليم الجيد والتدريب، ورفع مسـتوى مهارة القوة المنتجة، بالإضافة إلى زيادة قابلية انتقال الأيدي العاملة. مشكلة البحث:

تعاني الدول العربية من وجود فجوة معرفية ومهارية وتقنية كبيرة بين ما تلقاه خريجيها من تعليم وتدريب وبين احتياجات سـوق العمل، خاصـة في عصـر الأتمتة الجديد والذكاء الاصطناعي والروبوتات الثبيهة بالبشر، والتي يمكن أن تؤدي إلى فقدان بعض الوظائف وخروج نسبة كبيرة من

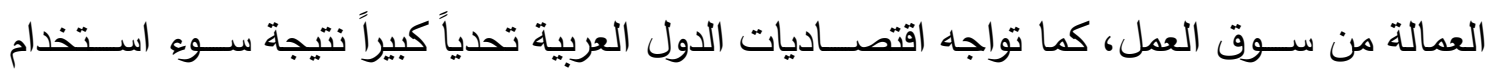
الموارد البشــرية والمادية، وعدم القدرة على ترتيب الأولويات في اســتخلال الموارد المتاحة ســـواء البشرية أو المادية وتوزيعها على الاستخدامات المتنافسة بما يحقق بناء اقتصاد فعّال وقوي، الأمر 
الذي يسـتوجب بحث أسـباب وجود هذه الفجوة وكيف يمكن معالجتها وضـــان حسـن إدارة الموارد البشرية بالدول العربية. أهمية البحث:

تأتي أهمية البحث انطلاقاً من أهمية بناء الطاقات البشـرية من خلال التعليم والتدريب، بما

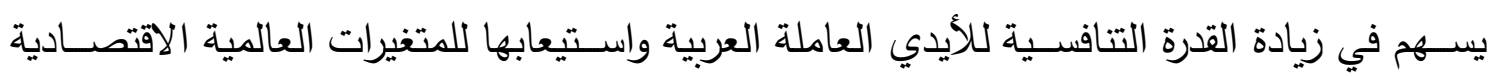

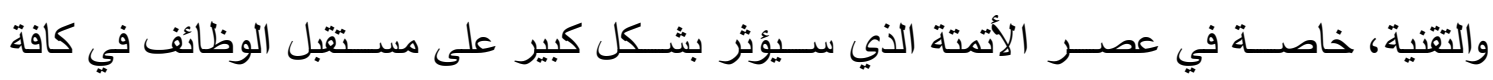
القطاعات الإنتاجية والتي ستؤدي إلى فقدان بعض الوظائف الحالية.

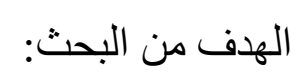

إلقاء الضوء على أبعاد الفجوة المعرفية والمهارية والتتنية لخريجي الجامعات، والتعرف على

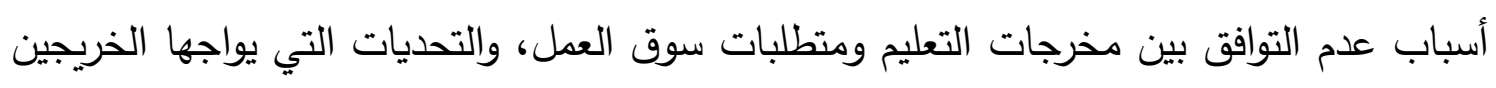

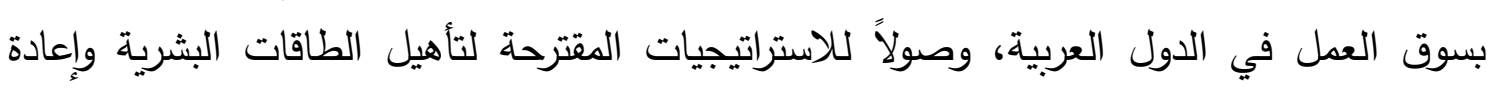

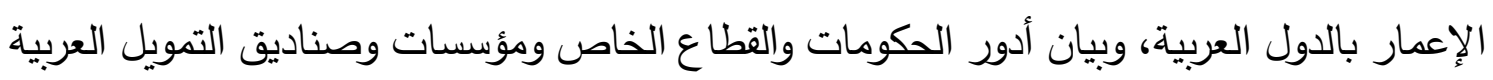

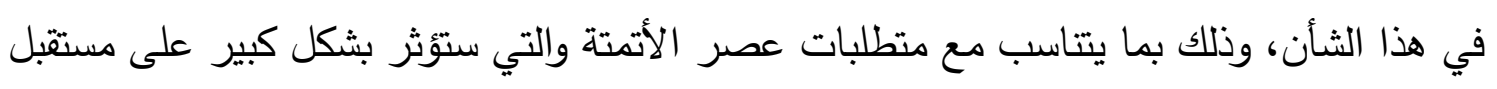
بعض الوظائف.

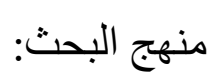
سيتم اتباع المنهج الوصفي التحليلي في دراستتا للواقع الحالي للتحديات التي تواجه الطاقات

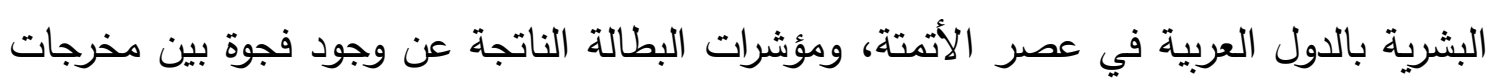
التعليم ومتطلبات سوق العمل.

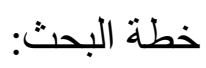

سنعرض في هذا البحث للوضع الراهن للطاقات البشرية بالدول العربية والتحديات التي تواجها

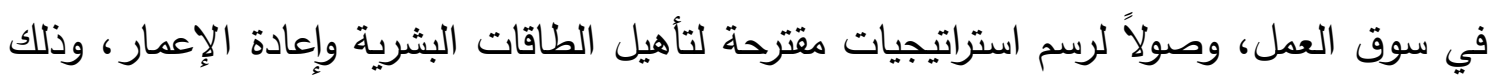

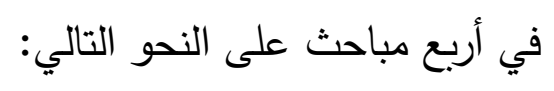
المبحث الأول: الوضع الراهن للطاقات البشرية بالدول العربية والتحديات التي تواجهها في أسواق العمل. المبحث الثاني: مستقبل الوظائف في عصر الأتمتة. المبحث الثالث: الاستراتيجيات المقترحة لتأهيل الطاقات البشرية وإعادة الإعمار . 
المبحث الرابع: دور الحكومات العربية والقطاع الخاص وصناديق التتمية العربية في رسم وتنفيذ تلك الاستراتيجيات

$$
\text { أولاً: دور الحكومات العربية }
$$

ثانياً: دور المنظمات العربية المتخصصة - المنبيقة عن جامعة الدول العربية

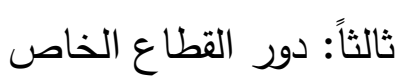
رابعاً: دور صناديق التمويل العربية 


\section{المبحث الأول}

$$
\text { و الوضع الر اهن للطاقات البشرية بالدول العربية }
$$

مقدمة: - مقام

لازال العنصر البشري في الدول العربية يعاني من وجود فجوة معرفية ومهارية وتقنية كبيرة

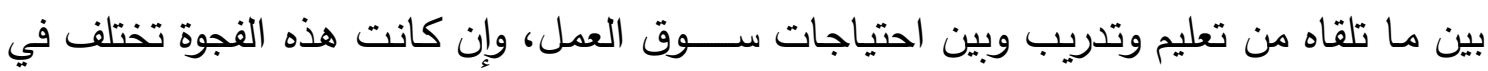
حجمها وتأثيراتها من دولة إلى أخرى. تيلم وتدربن

وســـعرض في هذا المبحث لأســباب وجود هذه الفجوة وآثارها، ثم نعرض للتحديات التي

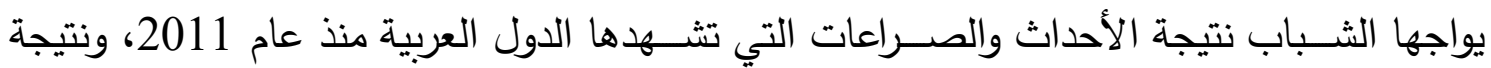

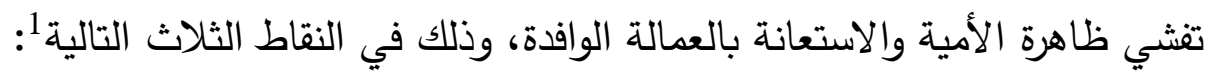

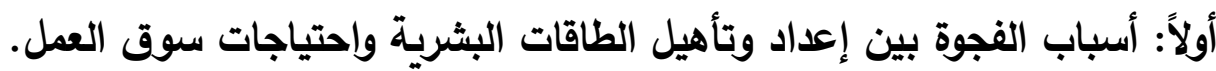
ثانياً: تفاقم ظاهرة البطالة كأثر لتلك الفجوة. ثالثاً: التحديات التي يواجها الثباب في المنطقة العربية. أو لاً: أسباب الفجوة بين إعداد وتأهيل الطاقات البشرية واحتياجات سوق العمل. تتلخص أهم أسباب ومكامن الخلل في العلاقة بين إعداد وتأهيل الطاقات البشرية العربية وسوق العمل سواء في الدول العربية أو الأجنبية فيما يلي:

\section{أ. المشكلات المرتبطة بمنظومة التعليم(2)}

\section{1. التركيز على الكم دون الكيف في العملية التعليمية.}

حيث يتم التركيز على زيادة أعداد الملتحقين في التعليم دون الاهتمام بجودة العملية التعليمية،

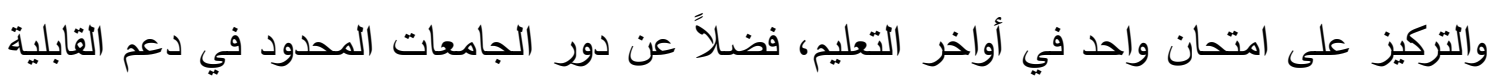

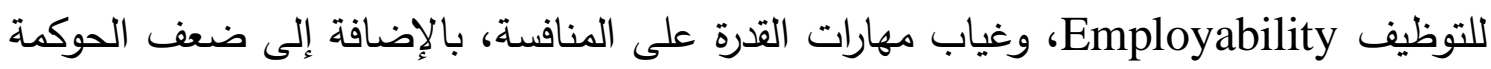
داخل المنظومة التعليمية العربية.

1 د. عادل السن: كيف تساهم الحكومات العربية والقطاع الخاص وصناديق التنمية العربية في رسم استراتيجيات تأهيل الطاقات البشرية وإعادة

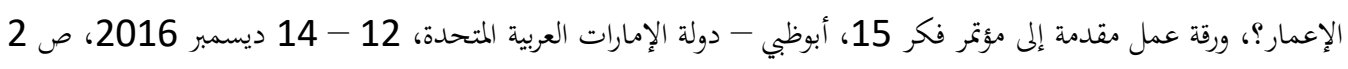

$$
\text { التقرير الاقتصادي العربي الموحد 2015، ص } 270 .
$$


2. تدني مخرجات المنظومة التعليمية وعدم قدرتها على الاستجابة لمتطلبات سوق العمل (3). فنظم التعليم والتدريب لا تلائم منطلبات ســـوق العمل. نتيجة تدني مخرجاتها وعدم قدرتها على الاستجابة لاحتياجات سـوق العمل من مهارات معرفية وقدرات على التعامل مع التكنولوجيات

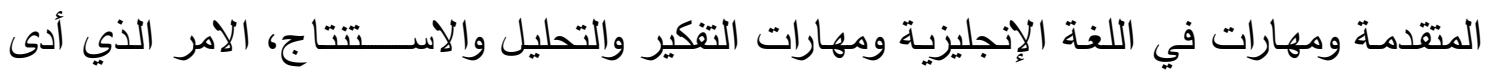

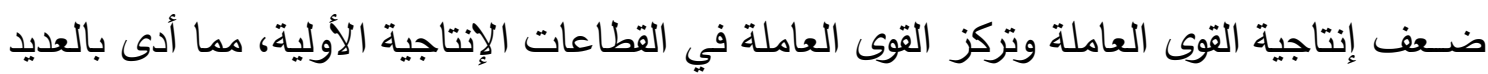
من الثركات والمؤسسات الاستثمارية بالدول العربية إلى الاستعانة بالعمالة.

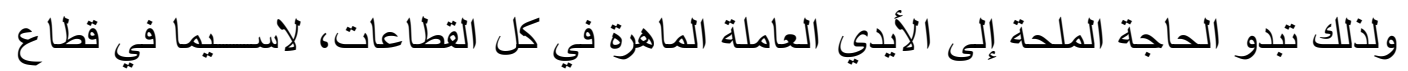

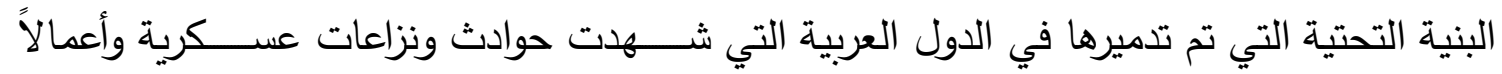
إرهابية. وعندما تتوقف هذه الحوادث ســـكون هناك حاجة إلى إعادة الإعمار ، وبذل الجها لتتمية

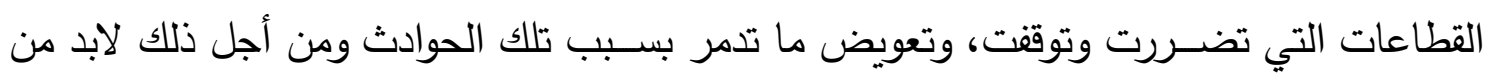

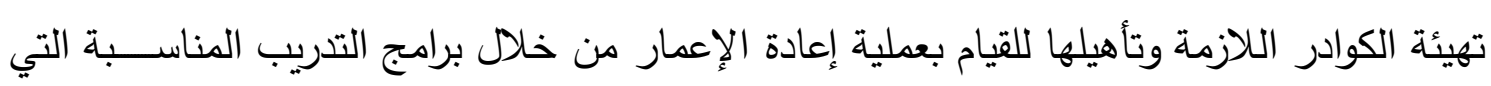
تؤدى لاكتساب الخبرات المطلوبة للقيام بهذه الأعمال.

3. الاهتمام بدراسة العلوم الإنسانية واهمال العلوم التطبيقية والعلمية، وسوء توزيع الثباب في

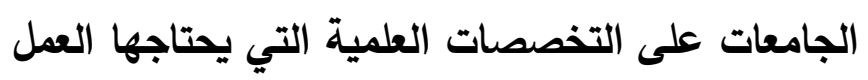

حيث يتجه الطلاب لدراسـة العلوم الإنسـانية كالآداب والفلسفة والمنطق وعلم النفس والتاريخ والجغرافيا، على حساب الاهتمام بدراسـة الموضوعات العلمية والتطبيقية في حقل التعليم الأكاديمي

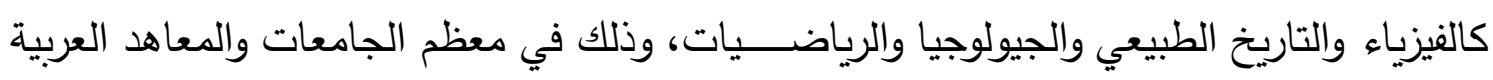

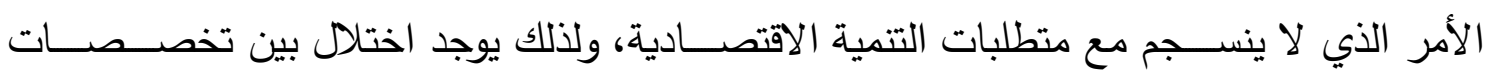

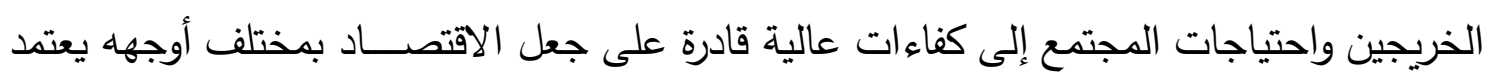

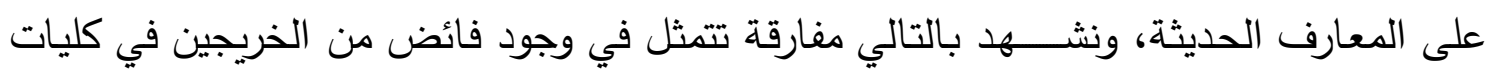

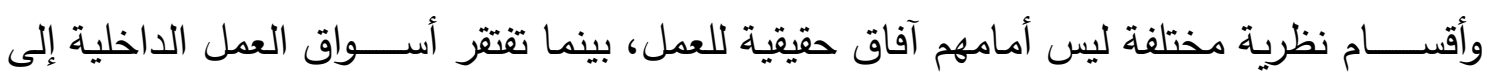

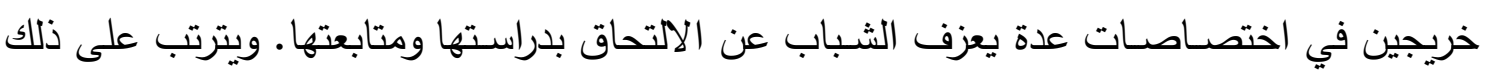
ظهور خلل في العلاقة بين الخريجين وسوق العمل أدى إلى تفاقم بطالة الخريجين. 


\section{4. - 5يل الثباب العربي للوظائف الحكومية}

يميل الثباب العربي، بصفة عامة، إلى الوظائف الحكومية. فمع أنها تقدم أجوراً أقل وترتكز

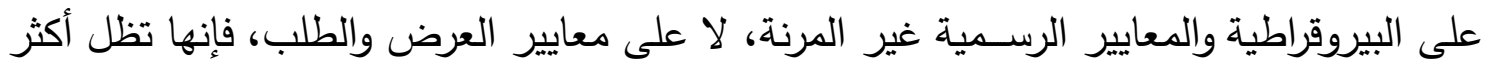

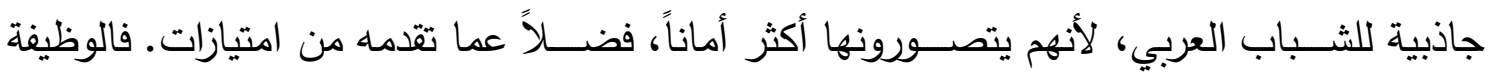

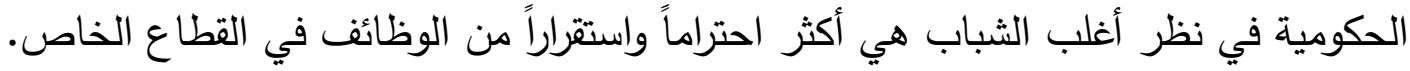

ب. المشكلات المرتبطة بمنظومة التدريب(4)

اتسمت نظم التعليم والتدريب في البلاد العربية بضعف الانتاجية، فمناهج التعليم في المنطقة

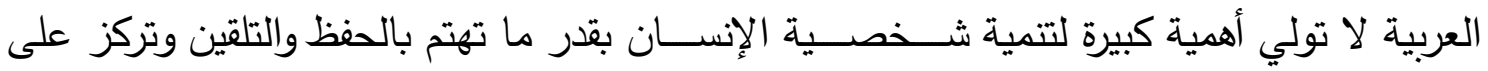
المعارف التي يمكن قياسها في الامتحانات التقليدية، ولا تركز على المهارات الوجدانية والاجتماعية

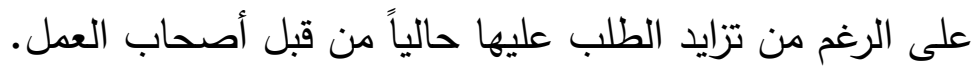
فنظم التعليم بمستوياتها المختلفة قد تجاهلت المهارات الإبداعية ومهارات الحياة والفنون. وقد ضــعفت الإمكانات الإبداعية لأجيال متعاقبة في المنطقة العربية. ولم تكتســـبـ هذه الأجيال خبرة المهارات والمعارف بالمعنى الواســـ، ومهارات التفكير والمهارات اللغوية في التواصــلـل والمهارات المعرفية العامة، وهي المهارات الداعمة للفاعلية المعرفية والإبداع والإنتاجية. كما أن ضآلة التمويل المخصص للتدريب والتأهيل ورفع كفاءة العاملين في مؤسسات القطاع

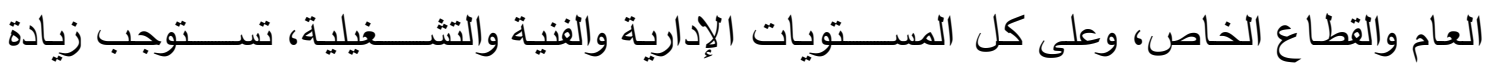
المخصصات المالية التي ترصد لهذه الغاية.

ثانياً: تفاقم ظاهرة البطالة كأثر لتلك الفجوة (5)

وقد كان من أهم أثار وتداعيات تلك الفجوة تفاقم ظاهرة البطالة، حيث بلغ معدل البطالة في الدول العربية عام 2014 حوالي 11.3\% . كما تركزت البطالة في تلك الدول بين الثــباب المتعلم. وقدت

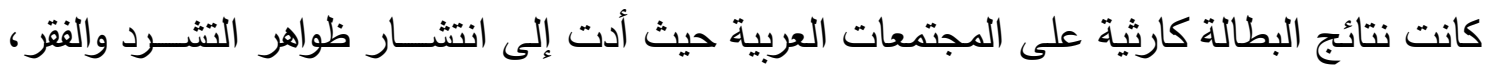
والعنف والإدمان، والتطرف والإرهاب، وارتفاع نســبة الجرائم، وهجرة العقول...وغيرها من الظواهر الاجتماعية السلبية التي تؤثر على المقدرات الاقتصادية للدول.

(4) د. فهد الفضـالة، التدريب أثناء الخدمة لشـاغلي الوظيفة العامة: دراسـة حالة لواقع التجربة الكويتية، سـسـلة دراسـات تنموية، المعهد

$$
\text { العربي للتخطيط، العدد (49) أكتوبر 2015. }
$$


ويمكن استخلاص الخلل بين منظومة إعداد وتأهيل الطاقات البشرية وأسواق العمل من المؤشرات

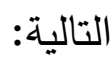

\section{خ مؤشرات التنمية البشرية.}

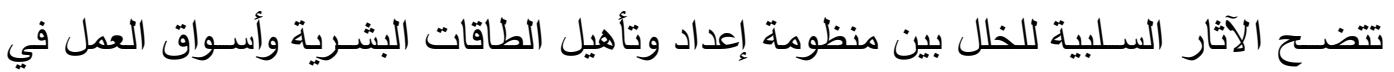

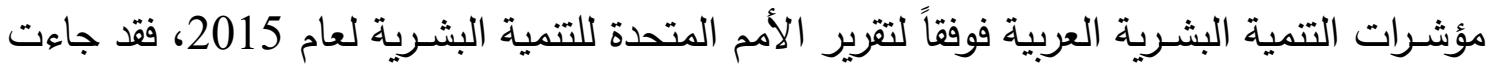

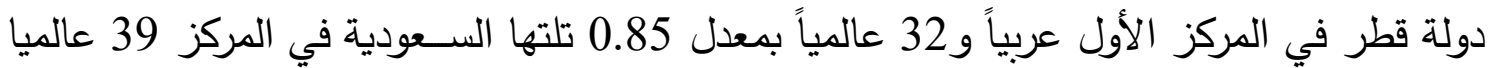

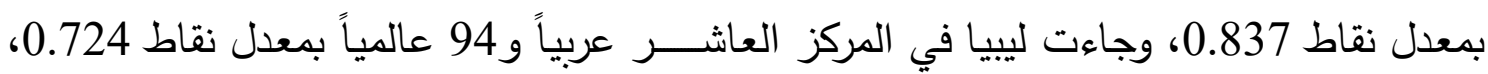

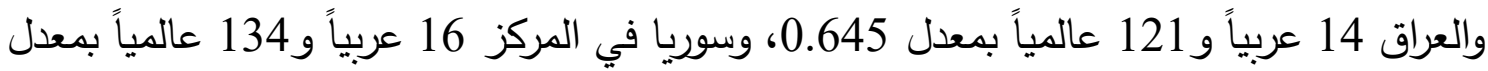

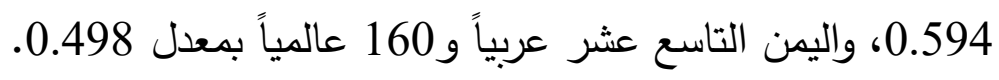

(6)

\begin{tabular}{|c|c|}
\hline Access to Advanced Education & Country \\
\hline 55.49 & United Arab Emirates \\
\hline 51.23 & Kuwait \\
\hline 25.03 & Tunisia \\
\hline 47.56 & Saudi Arabia \\
\hline 46.96 & Jordan \\
\hline 47.54 & Lebanon \\
\hline 20.05 & Morocco \\
\hline 24.41 & Algeria \\
\hline 39.32 & Egypt \\
\hline 36.03 & Iraq \\
\hline 7.96 & Djibouti \\
\hline 10.55 & Mauritania \\
\hline 5.29 & Yemen \\
\hline 45.99 & Bahrain \\
\hline 23.86 & Libya \\
\hline & \\
\hline & \\
\hline
\end{tabular}

(6) Social Progress imperative: SPI 2016. 


\begin{tabular}{|l|l|}
\hline & Oman \\
\hline 46.00 & Qatar \\
\hline 12.44 & Sudan \\
\hline
\end{tabular}

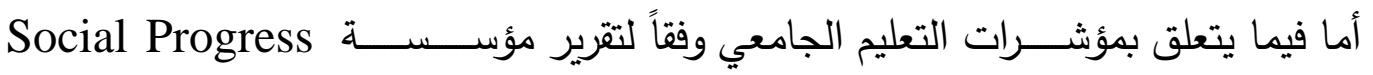

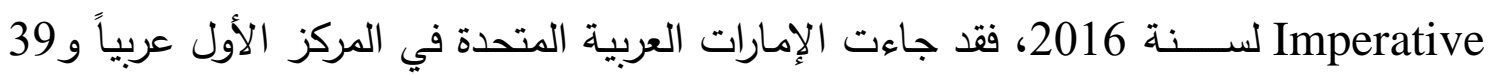
عالمياً بمعدل 55.49، تلتها دولة الكويت 45 عالمياً بمعدل 51.23، 51.20، وجاءت الأمات العراق في المركز

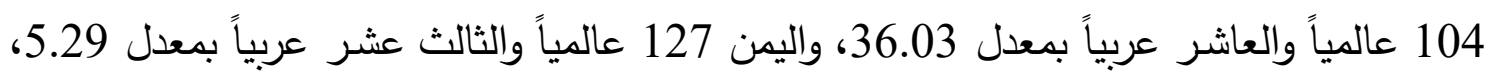
وليبيا في المركز 15 عربياً و147 عالمياً بمعدل 23.86.

مؤشرات الاستثمار . (7)

\begin{tabular}{|r|r|}
\hline \multicolumn{1}{|c|}{ Ease of Doing Business Rank } & \multicolumn{1}{|c|}{ Economy } \\
\hline 31 & United Arab Emirates \\
\hline 65 & Bahrain \\
\hline 68 & Qatar \\
\hline 70 & Oman \\
\hline 74 & Tunisia \\
\hline 75 & Morocco \\
\hline 82 & Saudi Arabia \\
\hline 101 & Kuwait \\
\hline 113 & Jordan \\
\hline 123 & Lebanon \\
\hline 129 & West Bank and Gaza \\
\hline 131 & Egyt, Arab Rep. \\
\hline 154 & Comoros \\
\hline 159 & Sudan \\
\hline 161 & Iraq \\
\hline
\end{tabular}

(7) Doing Business Report 2016. 


\begin{tabular}{|r|r|}
\hline 163 & Algeria \\
\hline 168 & Mauritania \\
\hline 170 & Yemen, Rep. \\
\hline 171 & Djibouti \\
\hline 175 & Syrian Arab Republic \\
\hline 188 & Libya \\
\hline
\end{tabular}

أما ما يتعلق بحالة الاسـتثمار، فقد أشـار تقرير Doing Business لعام 2016 تصــر

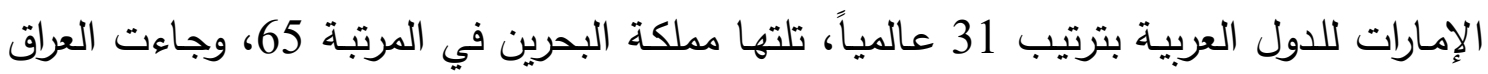
161 عالمياً، اليمن 170 عالمياً، سوريا 175 عالمياً، وليبيا 188 عالمياً.

ثالثاً: التحديات التي يواجها الثباب في المنطقة العربية

أ. الأحداث والصراعات التي تثهرها بعض الاول العربية منذ عام 2011.

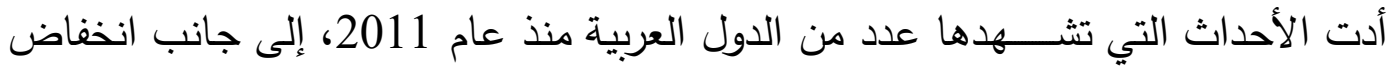

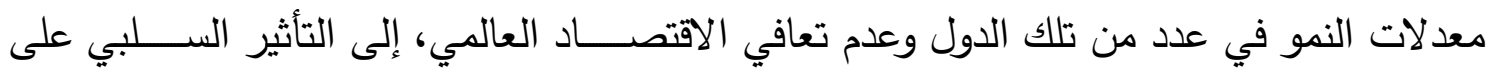

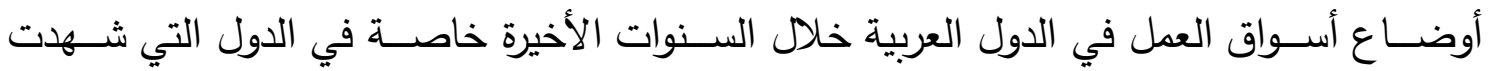

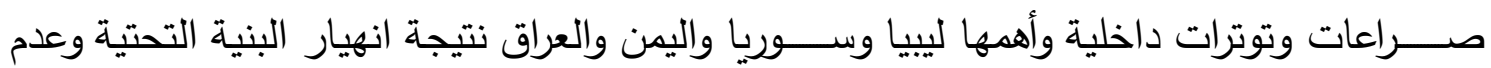
استقرار الأوضاع الأمنية بها حتى الآن.

كذلك فقد أدت الصــراعات والثورات إلى تردي الأوضـــــاع الأمنية واقصــاء مدن بأكملها من

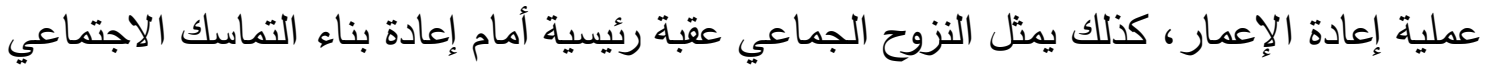

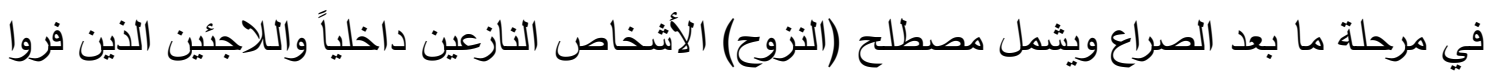

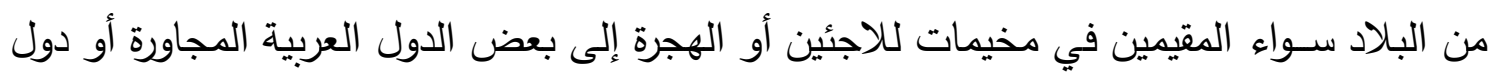

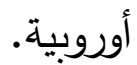

وقد أثرت تلك التتاقضـــات والصـــراعات الداخلية على البنى التحتية في تلك الدول وتزايت

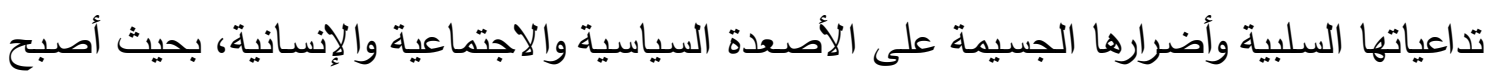


من الصـعب إيجاد التمويل المناسـب للحد من تلك التداعيات والخسـائر والأضــرار التي أصـابت

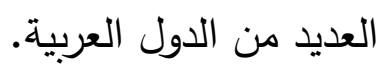
كما تشير إحدى الدراسات في معهد مقاييس الصحة والتقييم بجامعة واشنطن، والتي نشرتها لاونائ

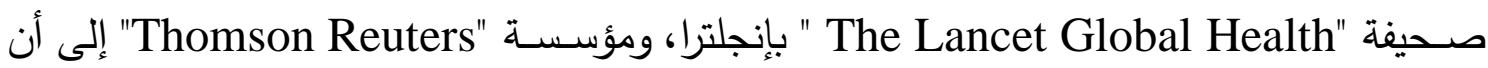
ثورات منطقة الثـرق الأوسـط وما أعقبها من نزاعات وحروب أهلية بين عامي 2010 و 2013 في العديد من دول المنطقة أدت إلى تراجع متوســـ الأعمار في مصــــر واليمن وتونس بمعدل ثلاثة أشهر ، بينما تراجع متوسط أعمار المواطنين في سوريا بمعدل 6 سنوات تقريباً.

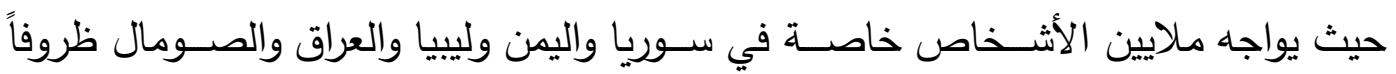

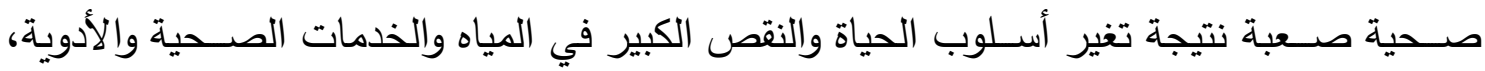

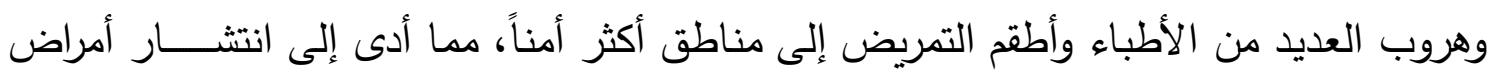
القلب والسكر والجلطات وظهور الأوبئة، وتزايد عبء الأمراض المزمنة والاصنابات.

ومن ثم لا يمكن إعادة الإعمار في ظل تلك الأوضاع، كذلك يمثل الأسلوب الذي يتم اعتماده

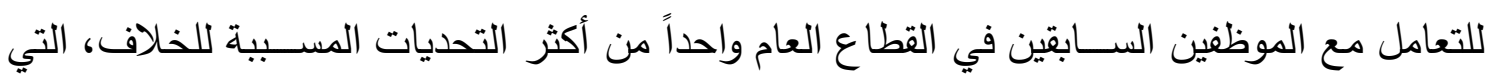
تقف في طريق إعادة الإعمار بعد انتهاء الصراع.

\section{ب. مشكلة الأمية والاستعانة بالعمالة الوافدة}

تواجه الدول العربية مشكلة انتشار الأمية، والتتي بلغت حوالى 30 في المئة أي حوالى مئة مليون عربي بحسب تقرير المنظمة العربية للتربية والثقافة والعلوم، هذا إضافة إلى مشكلة عمالة الأطفال حيث قدرت دراسة لليونيسف عام 2011 أن نسبة الأطفال الذين يعملون بين سن الخامسة

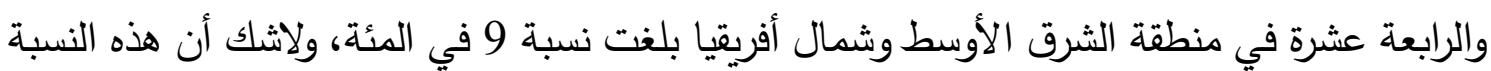

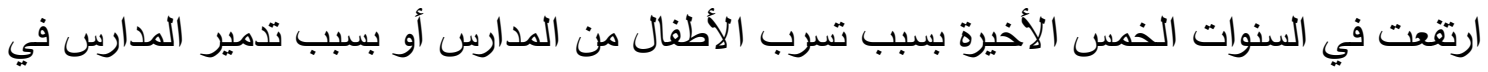

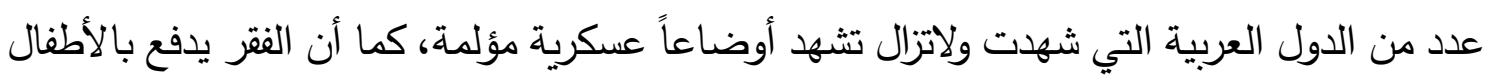
للبحث عن أعمال لا تتلاءم مع مستوى أعمارهم.

يضاف إلى ما تقدم موضوع العمالة الوافدة إلى الدول العربية وبخاصة لدى دول الخليج العربي حيث بلغت أكثر من ثلاثين مليون عامل، وهذه مشكلة لا يمكن التخفيف من حدتها إلا لإنال

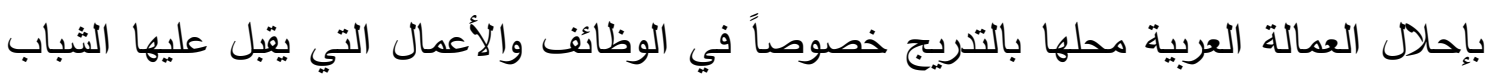

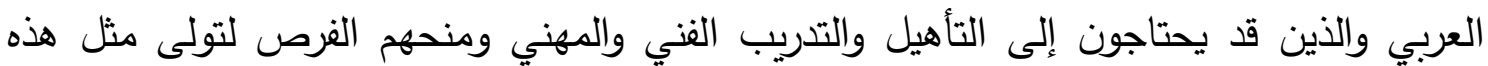




$$
\text { المبحث الثاني }
$$

مستقبل الوظائف في عصر الأتمتة

\section{مقدمة:}

الأتمتة (Automation) وتسمى أيضاً "التشغيل الآلي"، وفي بعض الأحيان "المكنة"، وهو

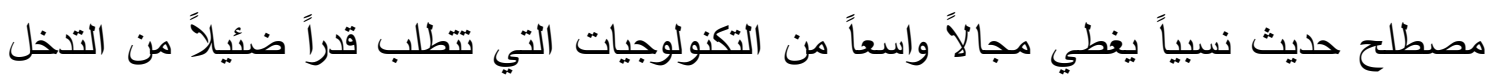
البشري، ويشمل ذلك أتمتة عمليات مثل التصنيع، وتكنولوجيا المعلومات، والتسويق، كما يغطي لتئي التطبيقات الثخصية مثل التشغيل الآلي للأجهزة المنزلية. وهكذا فإن الأتمتة تعني استخدام الكمبيوتر والأجهزة المبنية على المعالجات أو المتحكمات والبرمجيات في مختلف القطاعات الصناعية والتجارية والخدمية من أجل تأمين سير الإجراءات

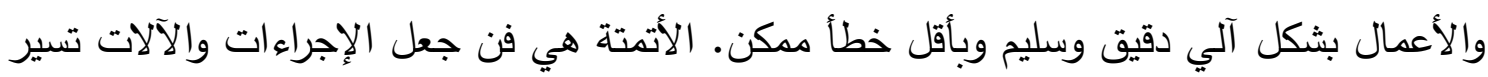
وتعمل بشكل تلقائي.

ويشمل تعريف الأتمتة، الروبوتات "الآلات التي تؤدي الأنشطة البدنية" والذكاء الاصطناعي

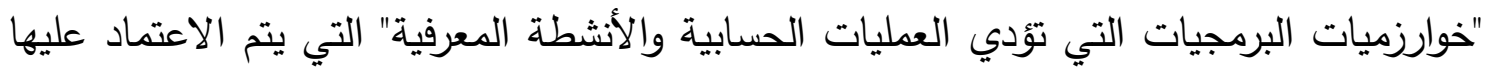

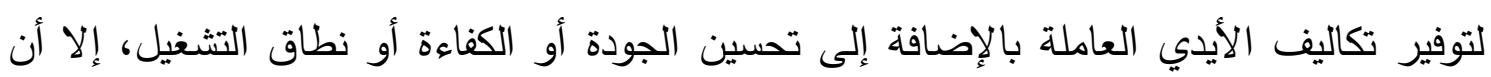
فقدان العمال لوظائفهم يصبح التحدي الكبير نتيجة الاعتماد على الأتمتة العافئ. وسنعرض في هذا المبحث للنقاط التالية: أولاً: تأثير الأتمتة والسيناريوهات المستقبلية لتطور الوظائف وأتمتة القوى العاملة في منطقة الثرق الأوسط. ثانياً: العوامل المؤثرة على وتيرة ومدى الأتمتة. ثالثاً: الأتمتة كمرك للإنتاجية والنمو الاقتصادي والوظائف المستقبلية.

أولاً: تأثير الأتمتة والسيناريوهات المستقبلية لتطور الوظائف وأتمتة القوى العاملة في منطقة الثرق الأوسط.

في إطار بحث تأثير الأتمتة والسيناريوهات المستقبلية لتطور الوظائف وأتمتة القوى العاملة

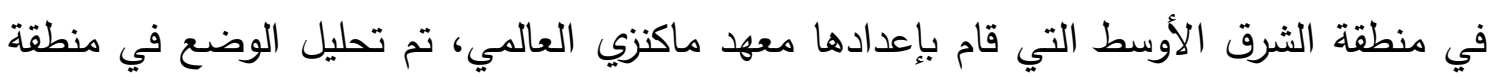
10 تقرير معهد ماكنزي العالمي حول مستقبل العمل، يناير 2017. 
الثرق الأوسط في ست دول هي البحرين، مصر ، الكويت، سلطنة عمان، المملكة العربية السعودية، والإمارات العربية المتحدة، وتضم هذه الدول الست مجتمعة أكثر من 147 مليون نسمة، ويبلغ ناتجها

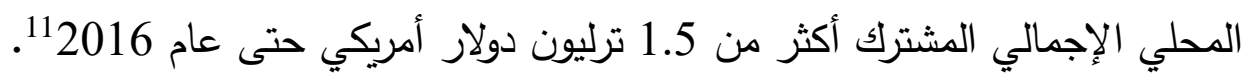

وقد أنتهى التقرير الذي أعده معهد ماكنزي العالمي المشار إليه حول مستقبل القوى العاملة

$$
\text { في منطقة الثرق الأوسط إلى ما يلي: }
$$

1. يمكن أتمتة 45\% من الأنشطة الموجودة في سوق العمل حالياً في دول منطقة الثرق الأوسط الست من خلال الاعتماد على التقنيات المتاحة حالياً.

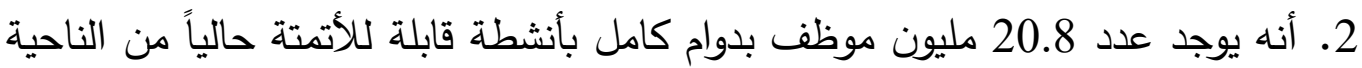

3. يمكن أتمتة القطاعات التي تتطلب أداء مهام روتينية مثل التصنيع والنقل والتخزين بالإضافة إلى قطاع المعلومات بنسبة تزيد عن 50\%، بئه بئما تتراوح نسبة أتمتة القطاعات التي تعتمد على التفاعل البشري والأنشطة الإبداعية وغير الروتينية كالفنون والترفيه

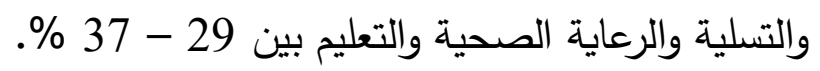

4. أن الخطر المحتمل لفقدان الوظائف لسبب تقنيات الأتمتة في أعلى مستوياته يكون بالنسبة للعمل والموظفين ذوي المستويات المنخفضة والمتوسطة من التعليم والخبرة،

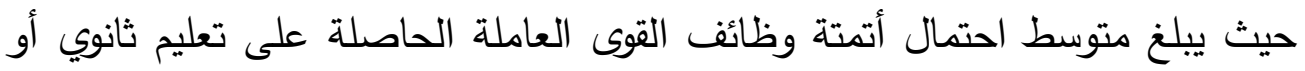

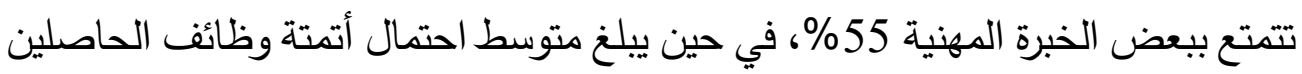

$$
\text { على مؤهل أدنى من التعليم الثانوي 50\% }
$$

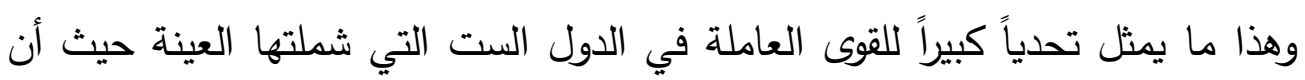
57\% من القوى العاملة في الدول الست تتدرج ضمن الفئتين السابقتين. كما تبين أن متوسط احتمال الأتمتة بالنسبة للحاصلين على شهادة بكالوريوس أو دراسات عليا هو 22\%.

5. من المتوقع أن تكون نسبة العمالة التي ستخرج من سوق العمل بحلول عام 2030 أقل

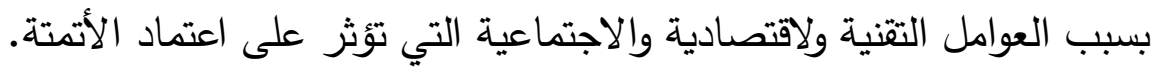

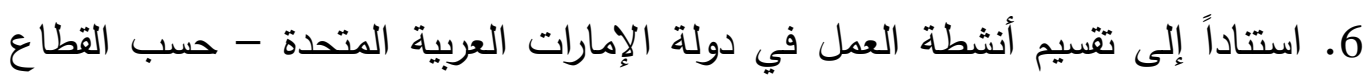
والوظيفة والتعليم - تشير التقديرات إلى أن أكثر من 93 الإنمارت من إمكانيات الأتمتة التي 
توفر العمالة في دولة الأمارات قابلة للتطبيق على وظائف يشغلها العمال المغتربون

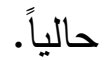

ونظراً لانخفاض إنتاجية العمل في بعض القطاعات وندرة المواهب المحلية النادرة للعمل

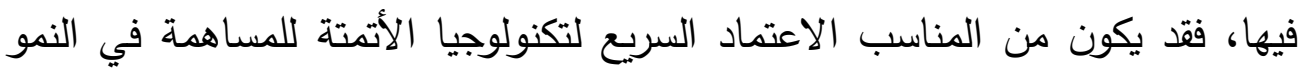
الاقتصادي وخلق وظائف مستقبلية ذات ميزة تتافسية على المستوى العالمي.

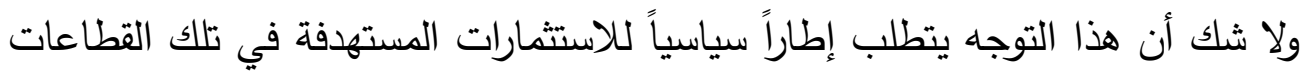

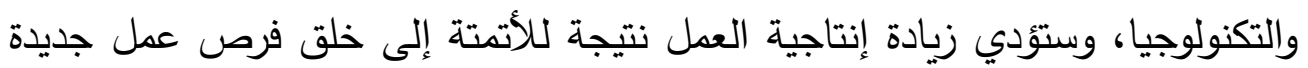

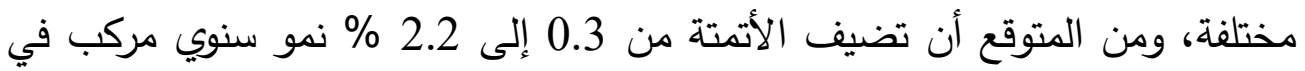
الإنتاجية بحلول عام 2030. كما أن التوازن بين تحسين الإنتاجية وتأثيرات استبدل اليد العاملة يختلف بشكل كبير

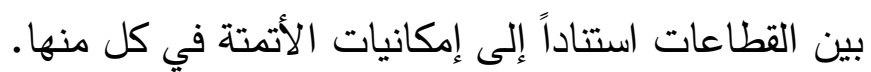

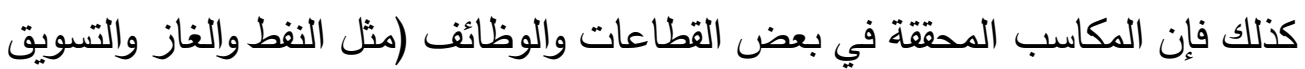
الاستهلاكي) والتي تؤدي دوراً أساسياً في الاقتصاديات الغنية بالموارد في منطقة الشرق الفات الأوسط تفوق بكثير آثار استبدال اليد العاملة.

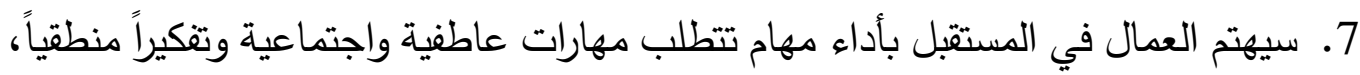

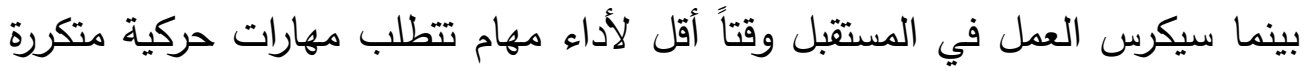

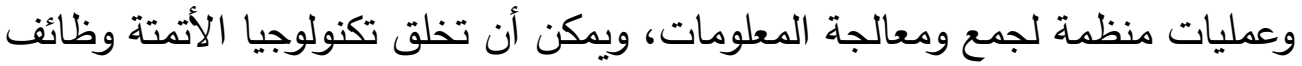

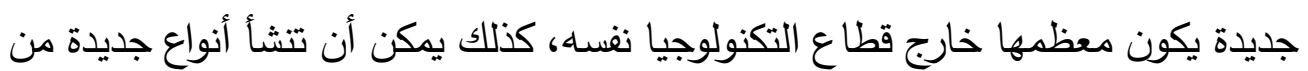
الوظائف تسىى الوظائف الوسيطة والتي تتطوي على مستويات تفاعل كبيرة بين الإنسان

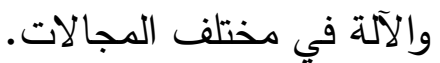




\section{ثانياً: العوامل المؤثرة على وتيرة ومدى الأتمتة.}

بناء على أبحاث معهد "ماكنزي" العالمي حول الاقتصاد العالمي، تم وضع سيناريوهات

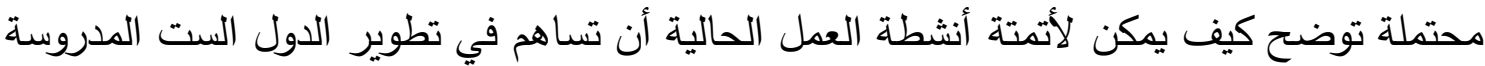
في منطقة الثرق الأوسط

ويستند نموذج أحاث معهد "ماكنزي" العالمي إلى خمسة عوامل واسعة النطاق ترسم دعالم مستقبل سيناريوهات الأتمتة، وتتمثل هذه العوامل فيما يلي:

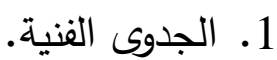

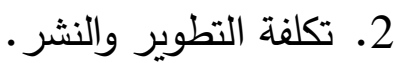

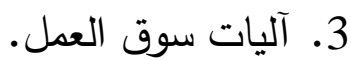

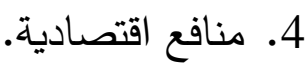

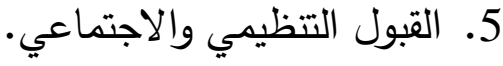




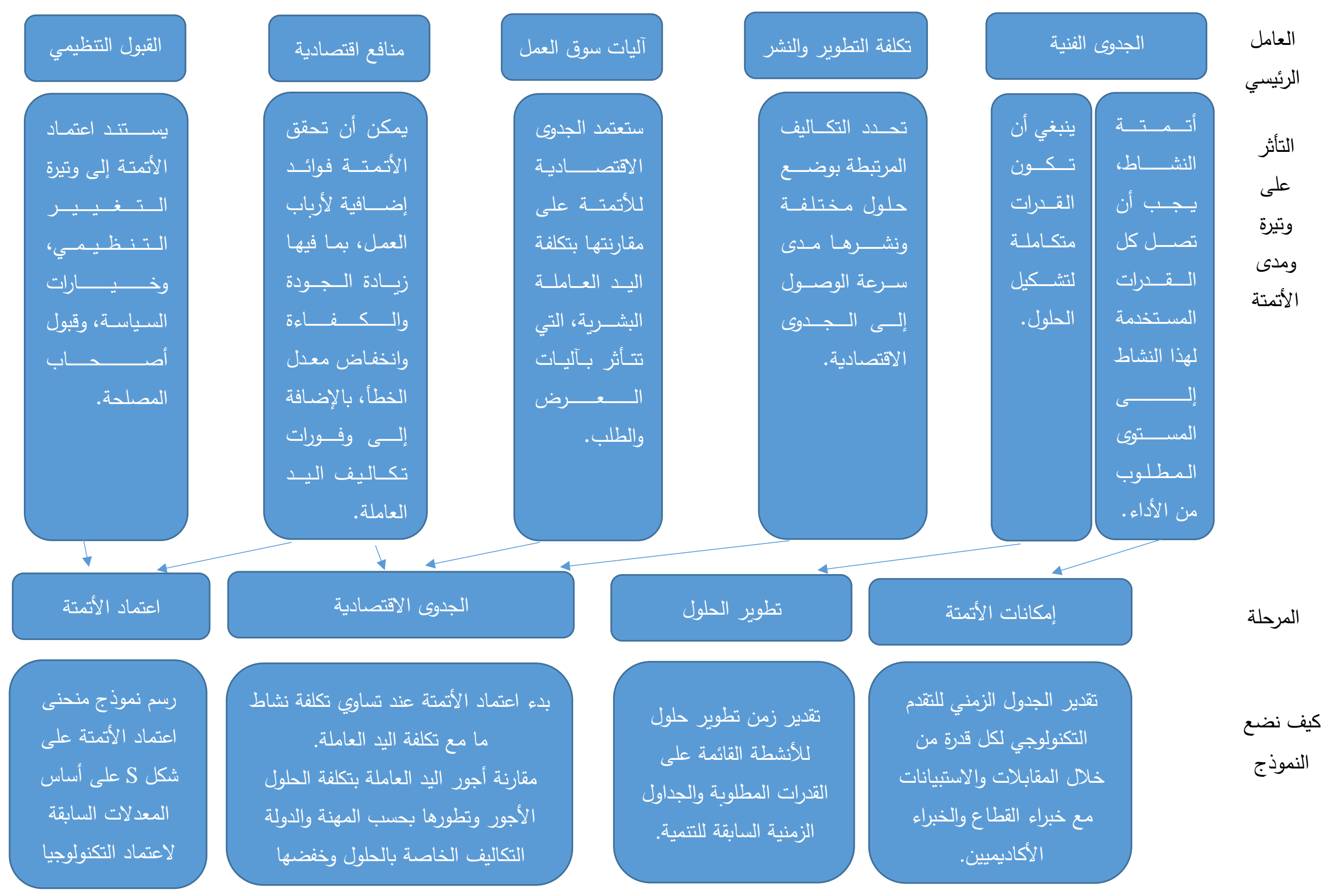


وتجدر الإشارة أن الأتمتة ستشكل قوة عالمية تؤثر على جميع الدول سواء كانت اقتصادات

ناشئة أو متقدمة.

ويمكن أن تشكل الأتمتة أكثر من 50\% من ساعات العمل في ثلثي الدول خلال عشرين

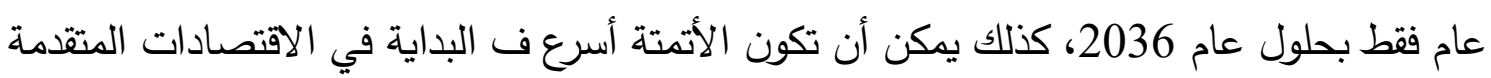

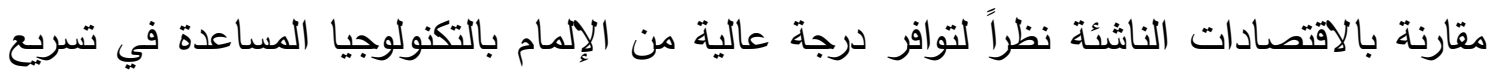

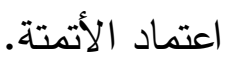

\section{ثالثاً: الأتمتة كمحرك للإنتاجية والنمو الاقتصادي والوظائف المستقبلية.}

يعتبر انتثار تكنولوجيا الأتمتة نقطة تحول كبيرة، بسبب إمكاناتها القادرة على إحداث تحولات

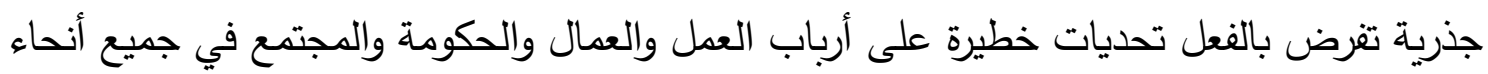
العالم على المدى القصير والمدى المتوسط، وفي الوقت نفسه يمكن أن تكون الزيادات المتعلقة

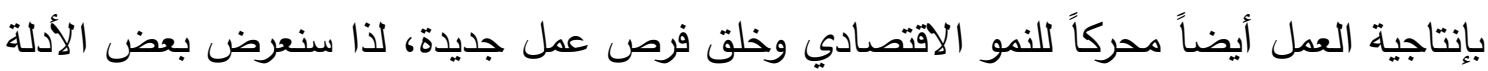
على ذلك ونناقش ما يترتب عليها من آثار تتعلق بطبيعة الوظائف في المستقبل.

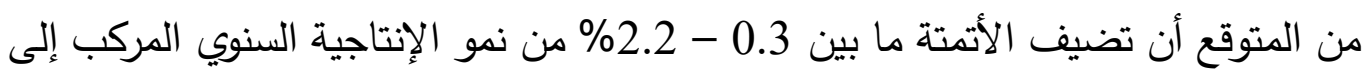

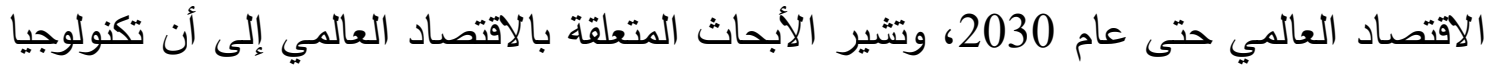

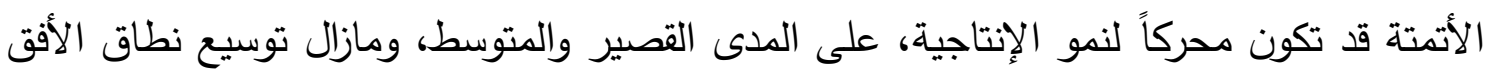

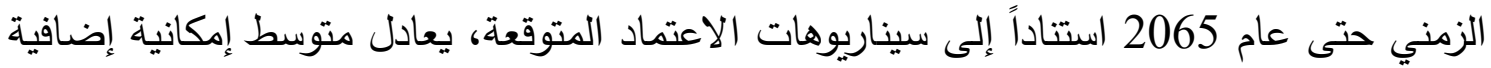
تتراوح ما بين 0.8 - 1.4\% من حيث نمو الإنتاجية السنوي المركب من الآن فصاعدأ13. تعد التقديرات بشأن الزيادة الإنتاجية المحتملة من الأتمتة على مدى الأعوام الخمسين المقبلة

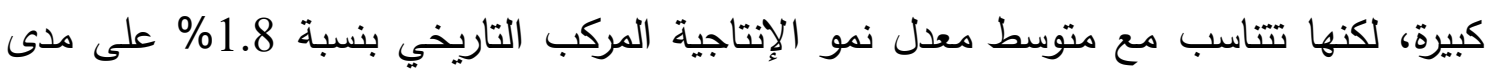

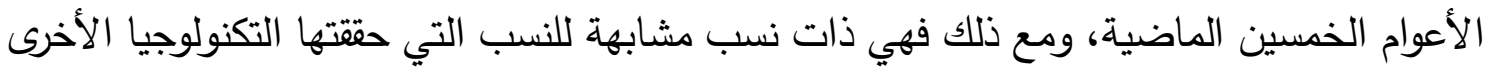

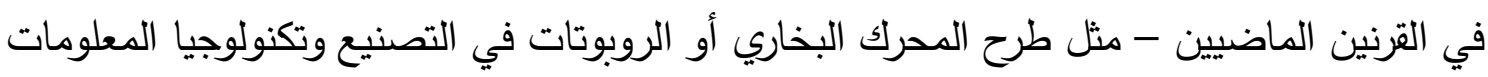

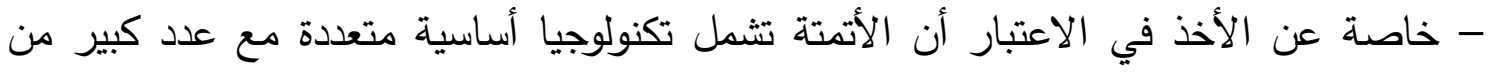
حالات الاستخدام في مختلف القطاعات. 
وستوفر الأتمتة مكاسب متعددة في الإنتاجية تتجاوز مجرد استبدال العمالة، حيث توجد

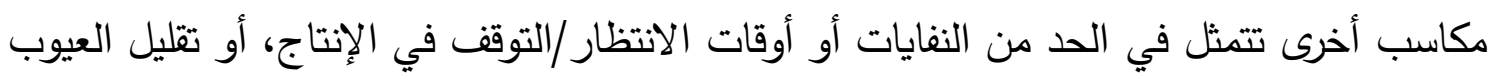
وتكاليف الصيانة، أو تحسين سرعة تسويق المنتجات الجديدة، أو زيادة الإيرادات لكل عميل. وإن كانت الأتمتة ستتسبب في تقليص فرص العمل، فإن بإمكان تكنولوجيا الأتمتة خلق فرص عمل جديدة صافية، معظمها خارج نطاق قطاع التكنولوجيا نفسه. وقد تم إجراء دراسة لتقنيتين في الولايات المتحدة، وهما الحواسب الثخصية والسيارات، لتقدير

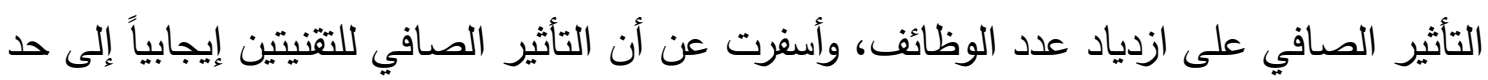

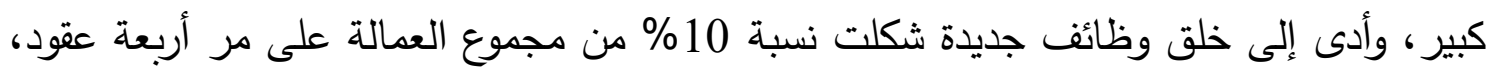

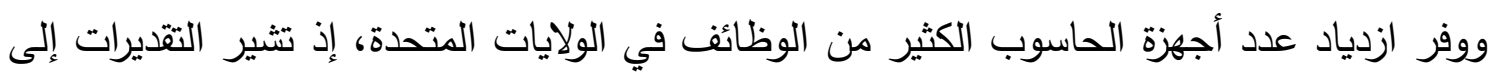

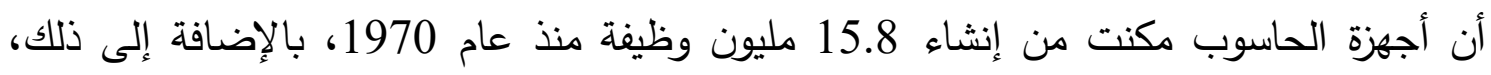

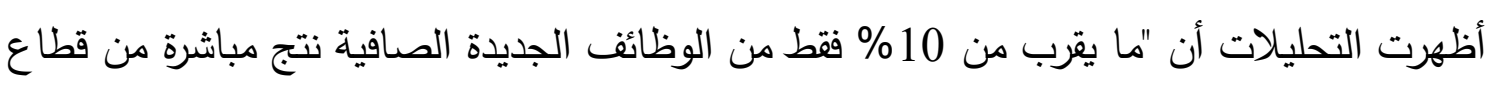

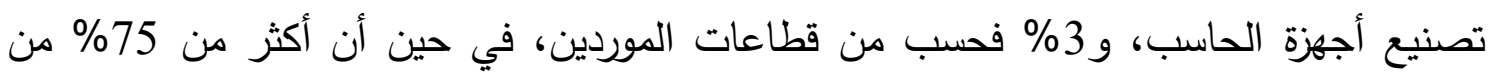
الأعمال الصافية التي تم ايجادها كانت في وظائف تستخدم أجهزة الحاسب". ولكن هل سيتكرر هذا النمط في مستقبل الوظائف بعصر الأتمتة خاصة في ضوء تزايد

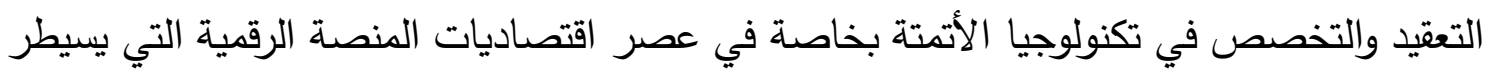
عليها عدد قليل من الأطراف في مجال التكنولوجيا ممن يملكون موارد لا يمكن التغلب عليها. وفي الوقت نفسه، لا تزال تكنولوجيا الأتمتة تتقدم بسرعة لتصبح متاحة أكثر لعدد أكبر من الأشخاص استناداً إلى طبيعتها الرقمية وقوة البروتوكولات مفتوحة الدصدر والثبكات والبنية التحتية

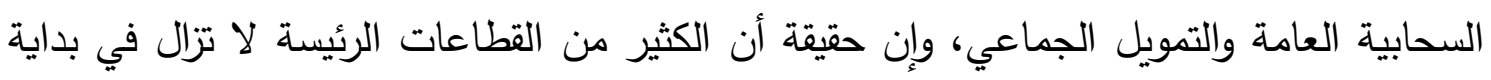

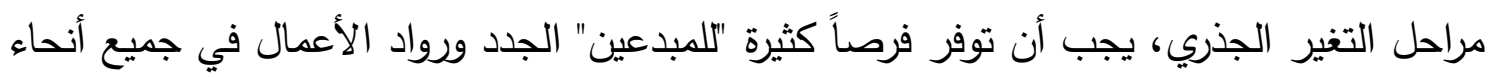
العالم، بما أن الحدود التقليدية للقطاع آخذة بالتلاشي أيضاً. وقد تتشأ أنواع جديدة من "الوظائف الوسيطة" من خلال تداخل التفاعل بين الإنسان والآلة في مختلف المجالات. وتتمثل الرؤية المتعلقة بالحواسب الثخصية بأن أكبر ازدياد في العمالة حدث في فئة

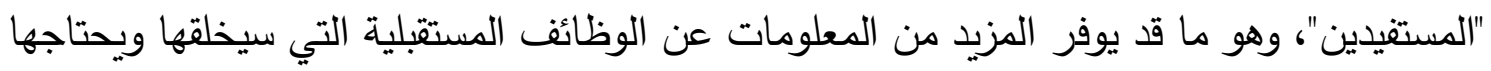

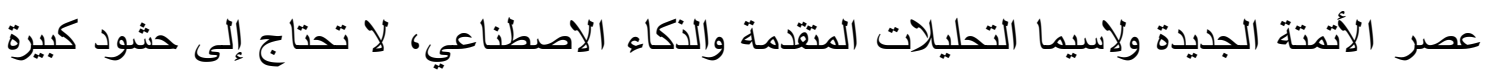

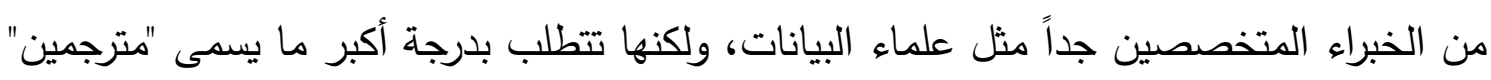


أو بعبارة أخرى الاختصاصيين الذين يستطيعون تحليل المعلومات ذات القيمة (Translators) المحتملة الأكبر واستخلاصها وايصالها بوضوح، ويتصفون بشكل خاص بأنهم يستطيعون الربط بين

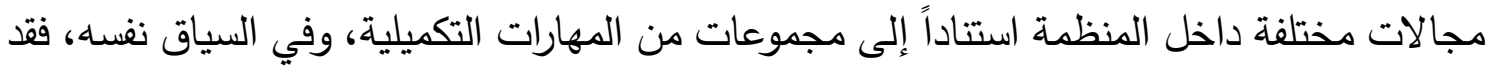

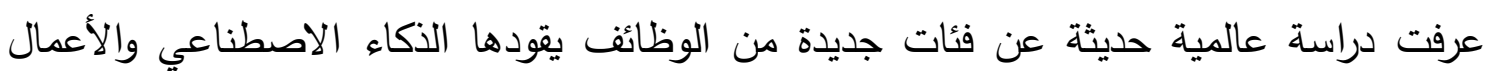
التجارية مثل "الددربين" و "المفسرين" و"الداعمين" كثلاث فئات جديدة مطلوبة على نطاق واسع لإطلاق التاع الإنتاجية وفرص تنمية الأعمال التجارية، ومن الجدير بالذكر أنه لا يفترض لبعض الوظنائف الونف الجديدة

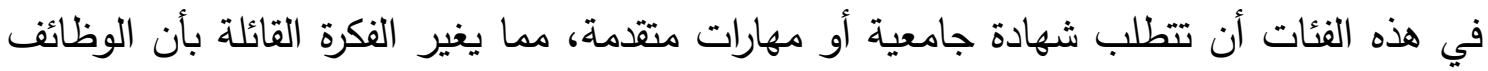
ذات المهارات العالية هي وحدها التي يمكنها البقاء.

ويتسم بدء عصر الأتمتة الجديد بالكثير من الثكوك، فعلى الرغم من أن إمكانية استبدال

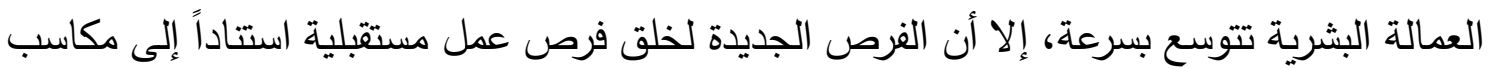

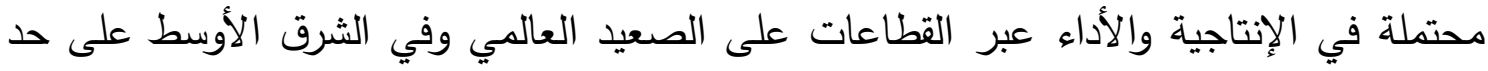
سواء، تواصل الظهور ، وسيلزم المزيد من الوعي والبحث لمعرفة المزيد عن الآليات المعقدة الناشئة، لألئه

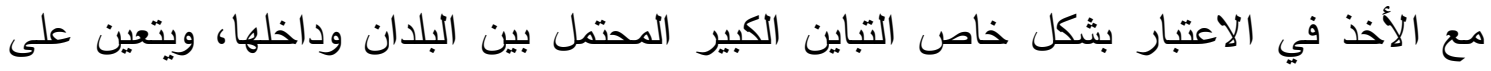
الحكومات والثركات والمجتمعات في الدول سريعة النمو في الثرق الأوسط أن تتتبه بشكل خاص

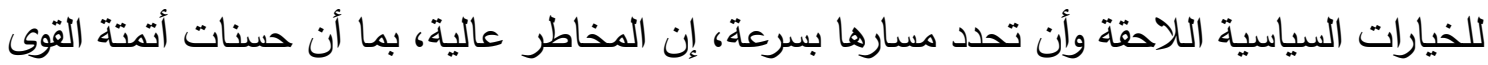

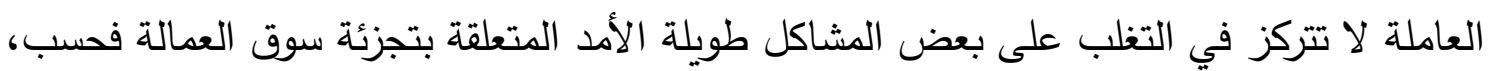

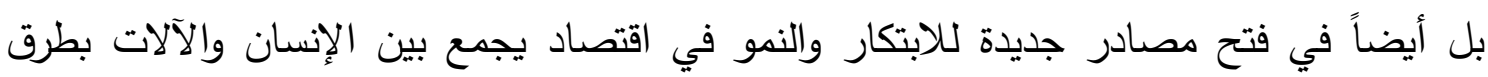
جديدة.14.

14 جان بيتر أوس ديم مور Jan Peter Aus Dem Moore، فيناي شاندران Vinay Chandran، يورج شوبيرت Jorg Schubert مستقبل الوظائف في الثرق الأوسط، القمة العالمية للحكومات، يناير 2018، ص 28-28 
الاستر اتيجيات المقترحة لتأهيل الطاقات البشرية و إعادة الإعمار

في ضــــوء التحديات الســابق عرضـــها، والتي تثــير إلى وجود عوائق داخل المنظومة

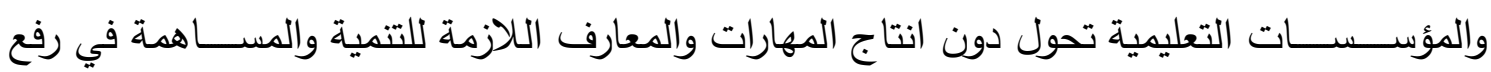

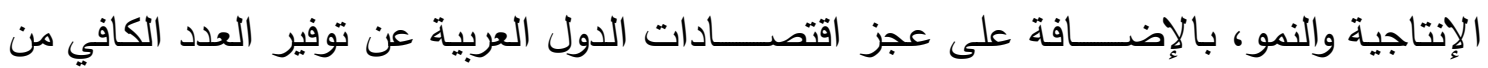

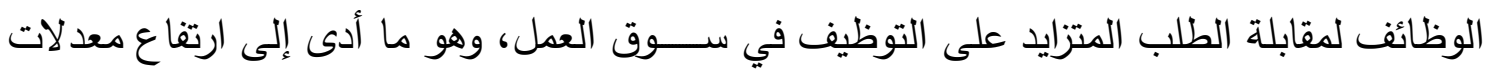

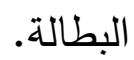

فقد أضحى الاهتمام بوضع الاستراتيجيات المناسبة لتأهيل الطاقات البشرية المنتجة ضرورة ملحة لتحقيق التتمية البشرية وصولاً للتمية الثاملة المستدامة. وتجدر الإثارة إلى أن مستوى تأهيل تلك الطاقات يرتكز بصفة أساسية على ما يلي:

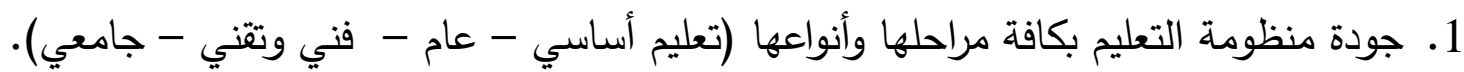

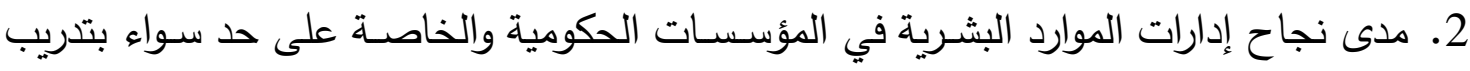

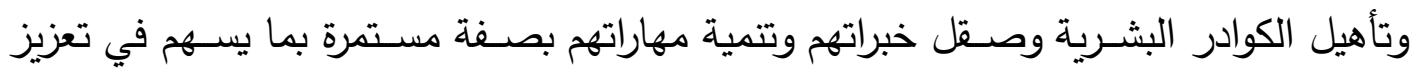

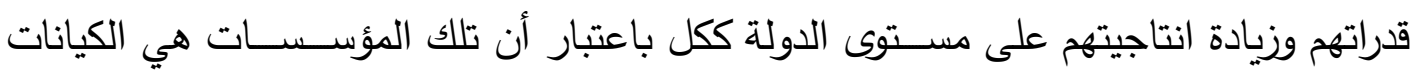
الفردية التي تتكون منها اقتصاديات الدولة.

وكذلك فإن متطلبات ومستوى تأهيل تلك الطاقات تختلف بين الدول العربية وفقاً للاتي:

$$
\text { 1. المستوى الاقتصادي لكل دولة (غنية - متوسطة - فقيرة). }
$$

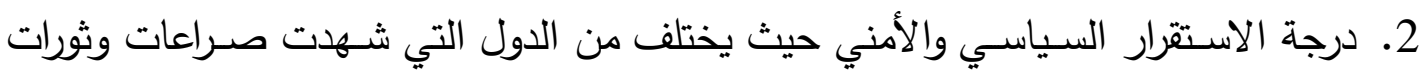

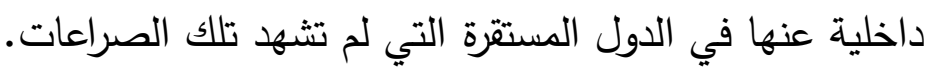

ومن ناحية أخرى فإن مفهوم إعادة الإعمار تختلف أولوياته وتحدياته من الدول المستقرة عنها

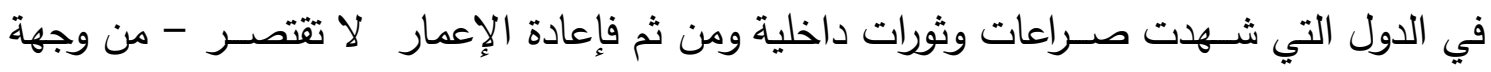

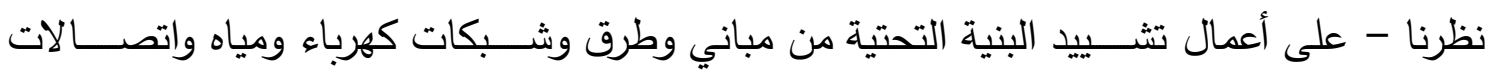

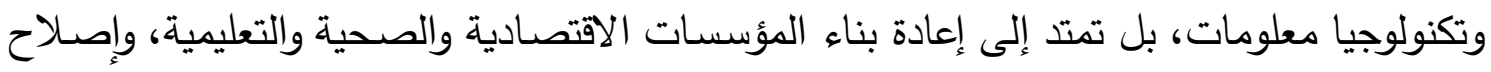

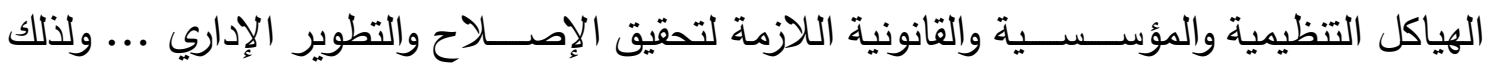

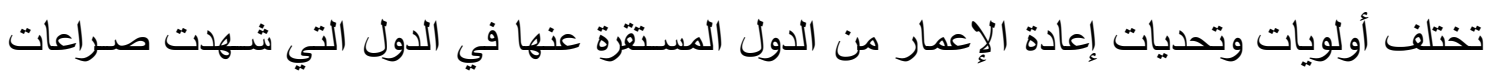


والواقع أن تأهيل الطاقات البشـــرية وإعادة الإعمار وجهان لعملة واحدة، فلا يمكن تحقيق إعادة الإعمار بمفهومه الثامل والواسع دون وجود طاقات بشرية مؤهلة وقادرة على ذلك. وحتى يمكن رسم استراتيجيات لتأهيل الطاقات البشرية وإعادة الإعمار ، فإنه يتعين رسم تلك لكات الاستراتيجيات في إطار خطة التنمية المستدامة لعام 2030 الصادرة بقرار الجمعية العامة للأمم المتحدة في 25 أيلول/ سبتمبر 2015 التي اهتمت بقضايا تأهيل الطاقات البشرية وإعادة الإعمار وبناء اقتصاد المعرفة، وأكدت على أن البطالة هي أهم مظاهر وأثار الخلل في تأهيل الطاقات

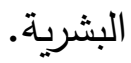
وذلك في الأهداف أرقام (4، 8، 9) من أهداف التتمية المستدامة والتي ركزت على أهمية التعليم في بناء القدرات البشرية، وتوفير اقتصاد حقيقي منتج لاستيعاب العمالة المؤهلة، بالإضافة

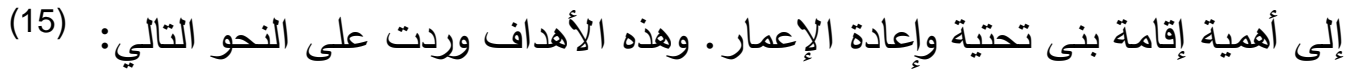
الهذف 4: ضمان التعليم الجيد المنصف والثامل للجميع وتعزيز فرص التعلم مدى الحياة للجميع.

الهاف 8: تعزيز النمو الاقتصادي المطرد والثامل للجميع والمستدام، والعمالة الكاملة والمنتجة، وتوفير العمل اللائق للجميع.

الهاف 9: إقامة بنى تحتية قادرة على الصمود، وتحفيز التصنيع المستدام الثامل للجميع،

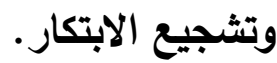

وهكذا فإنه يمكن رســـم اســتراتيجيات تأهيل الطاقات البثــرية وإعادة الإعمار ، من خلال اتباع

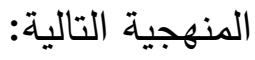
أ. تحديد الأهداف الاستراتيجية التي تتمثل فيما يلي: 1. بناء اقتصــاد المعرفة وســـ الفجوة المعرفية والمهارية والفنية والتتنية للكوادر البثـرية العربية. عن طريق اصلاح وتطوير المنظومة التعليمية من أجل تحسين أفاق التشغيل. 2. وجود اقتصـاد حقيقي منتج ومؤسـسـات انتاجية زراعية وصـناعية وتجارية وخدمية يسـتوعب الطاقات البثـرية التي تم إعدادها وتأهيلها، من خلال بيئة أعمال جاذبة للاسـتثمارات الوطنية والأجنبية على المستويين التثريعي والإداري. 
3. إعادة الإعمار بمفهومه الثـامل في الدول العربية بصـفة عامة، والبنى التحتية في الدول التي شهدت صراعات وثورات داخلية بصفة خاصة.

ب. وضــع مؤشـرات قياس نتائج الأهداف التي تم وضـعها بالتزامن مع بناء نظام حوكمة فعال، كونه الترجمة الحقيقية لرؤية قابلة للتنفيذ.

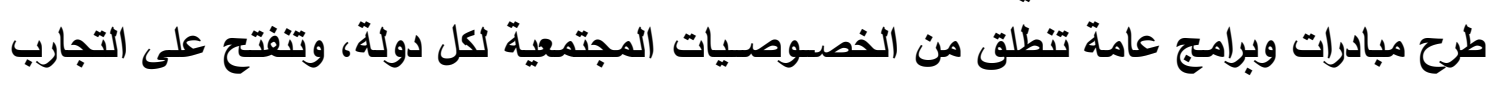
العالمية للاستفادة منها. وهي: (16) 1. إصلاح وتطوير نظم وسياسات التعليم الأساسي والفني والمهني إلى جانب تغيير سياسات نظم

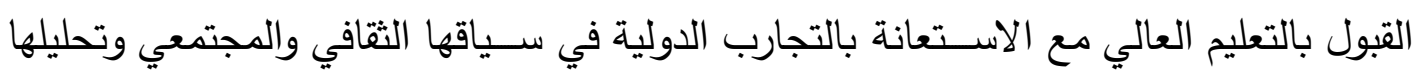

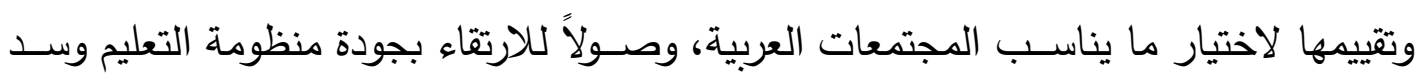

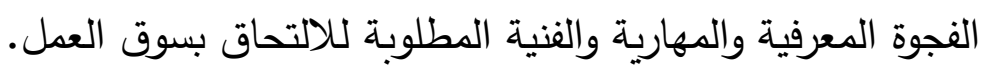
2. تفعيل دور إدارات الموارد البثـرية بالمؤسـسـات والأجهزة الحكومية لتأهيل الطاقات البشـرية

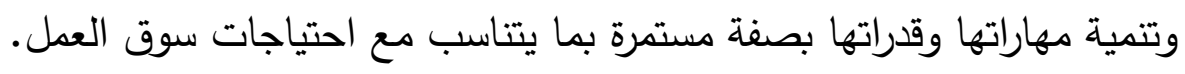
3. توفير بيئة أعمال جاذبة للاســتثمارات الوطنية والأجنبية على المســتوى التثــريعي والإداري والأمني، واعتماد سياسات كلية وقطاعية.

4. البحث عن حلول ومعالجات سـريعة وفعالة، للأوضـاع المرتبكة التي تمر بها العديد من الدول العربية لاسيما الدول التي تضررت بشدة نتيجة الإرهاب والصراعات الداخلية، وذلك من خلال

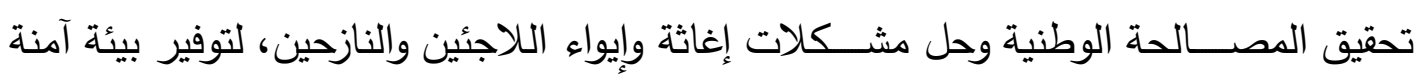
نسبياً على المستوى السياسي والاقتصادي والاجتماعي في تلك الدول. وتأسيساً على ما تقدم، سيتم عرض التحديات الأسـاسية أمام كل هدف استراتيجي، ووضـع حزمة

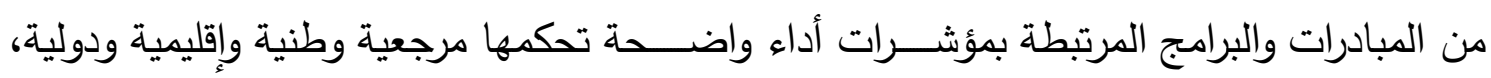

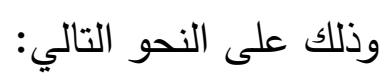

أولاً: الفجوة المعرفية والتقنية والمهارية والفنية للكوادر البشرية العربية. ثانياً: عدم وجود اقتصاد حقيقي منتج وبيئة أعمال تستوعب الطاقات البشرية المؤهلة. ثالثاً: تحديات إعادة الإعمار في الدول التي شهدت صراعات وثورات داخلية.

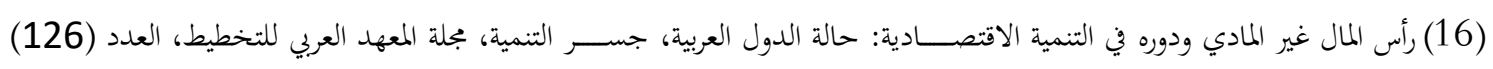
أكتوبر 2015. 
أو لاً: الفجوة المعرفية و التقنية و المهارية والفنبة للكو ادر البشرية العربية.

\begin{tabular}{|c|c|c|c|}
\hline مؤشرات الأداء & البرامجج & المبادرات & 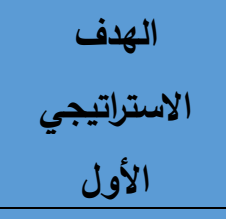 \\
\hline 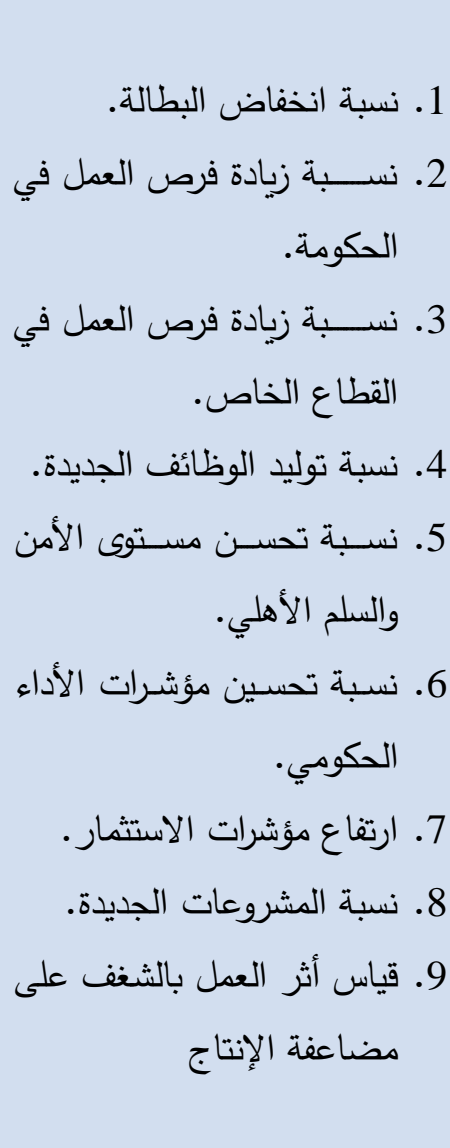 & 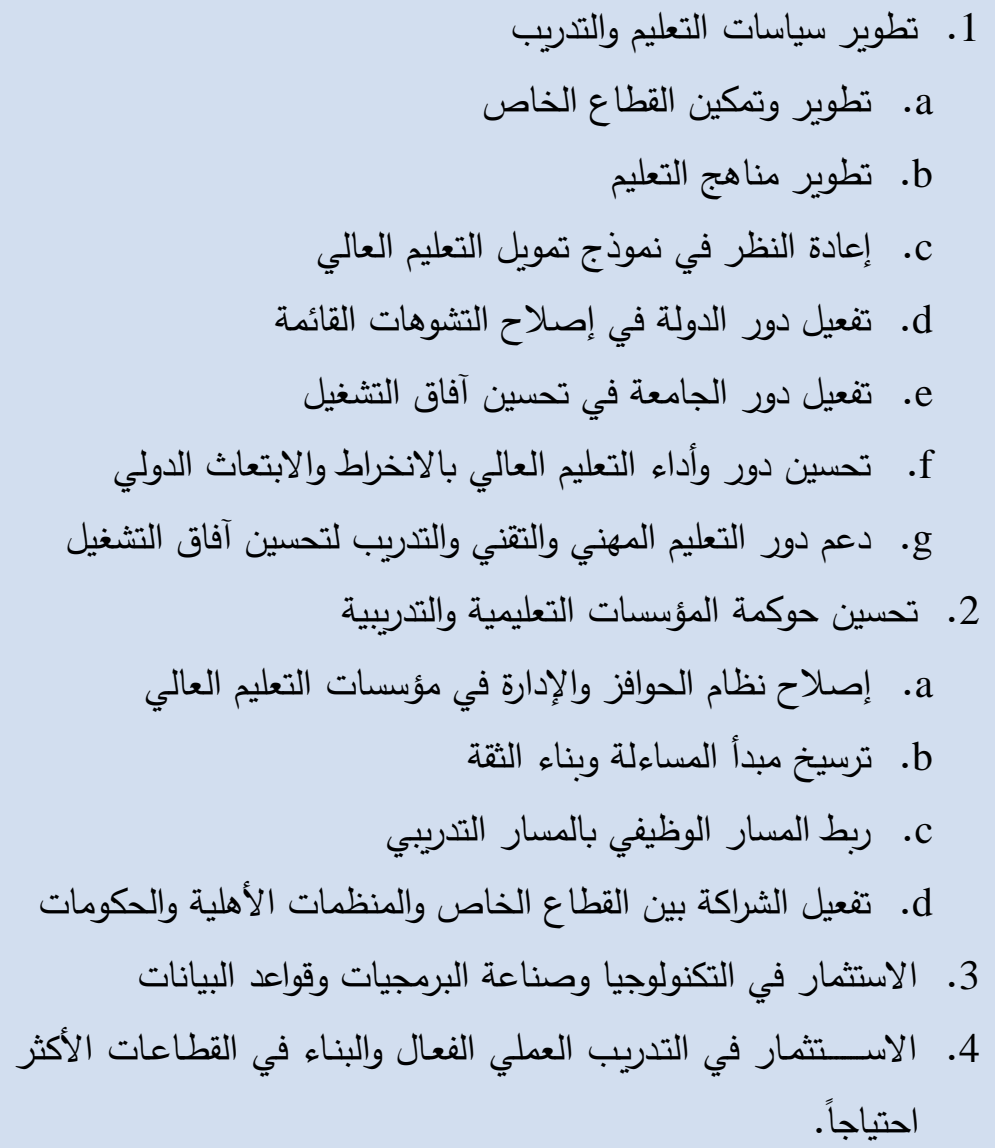 & 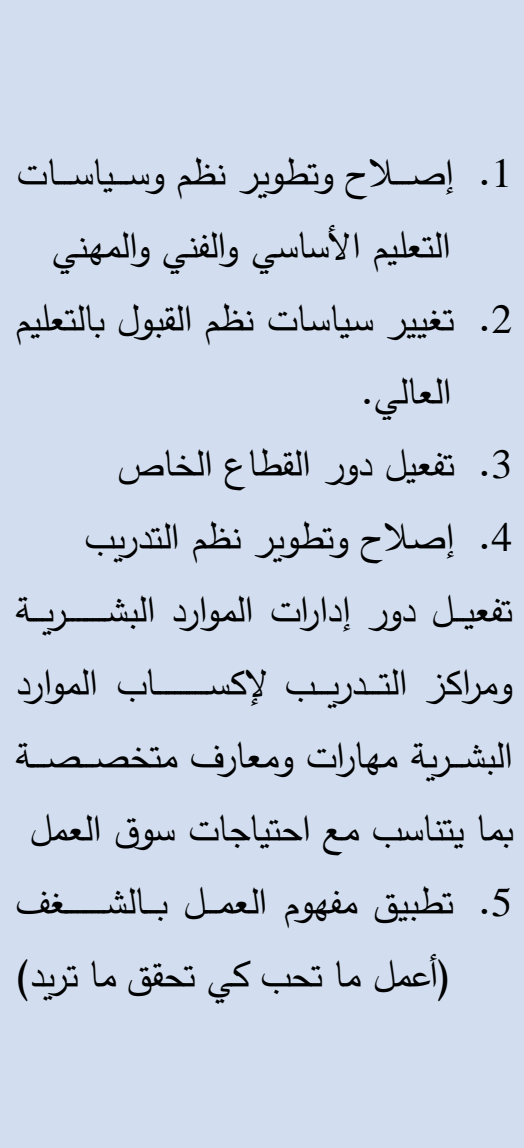 & المباء اقتصـــــاد \\
\hline
\end{tabular}


ثانياً: عدم وجود اقتصاد حقيقي منتج وبيئة أعمال تسنو عب الطاقات البشرية المؤهلة.

\begin{tabular}{|c|c|c|c|}
\hline مؤشرات الأداء & البرامج & المبادرات & الثاني \\
\hline 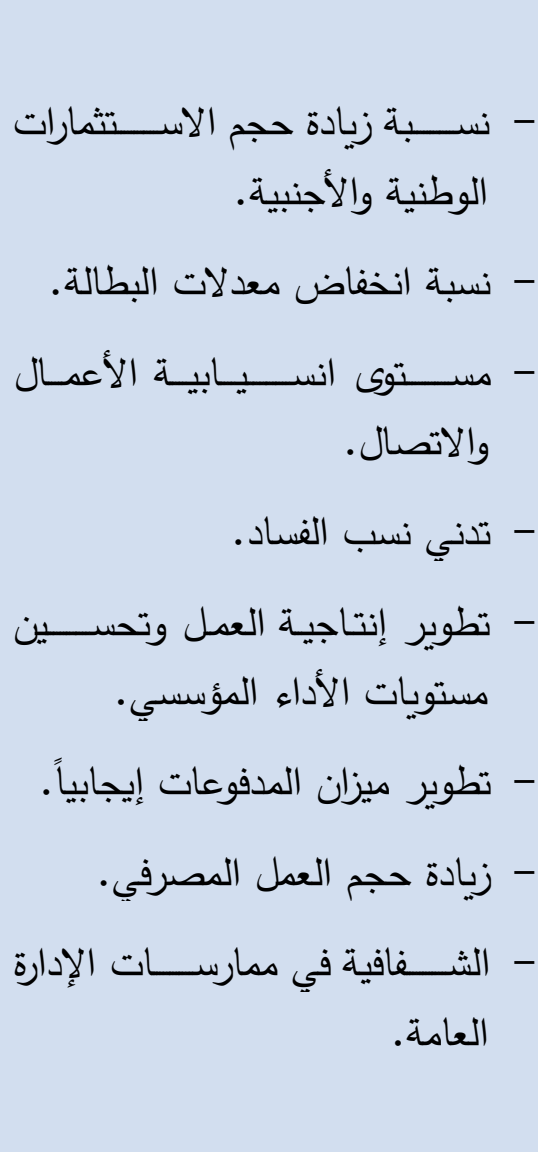 & 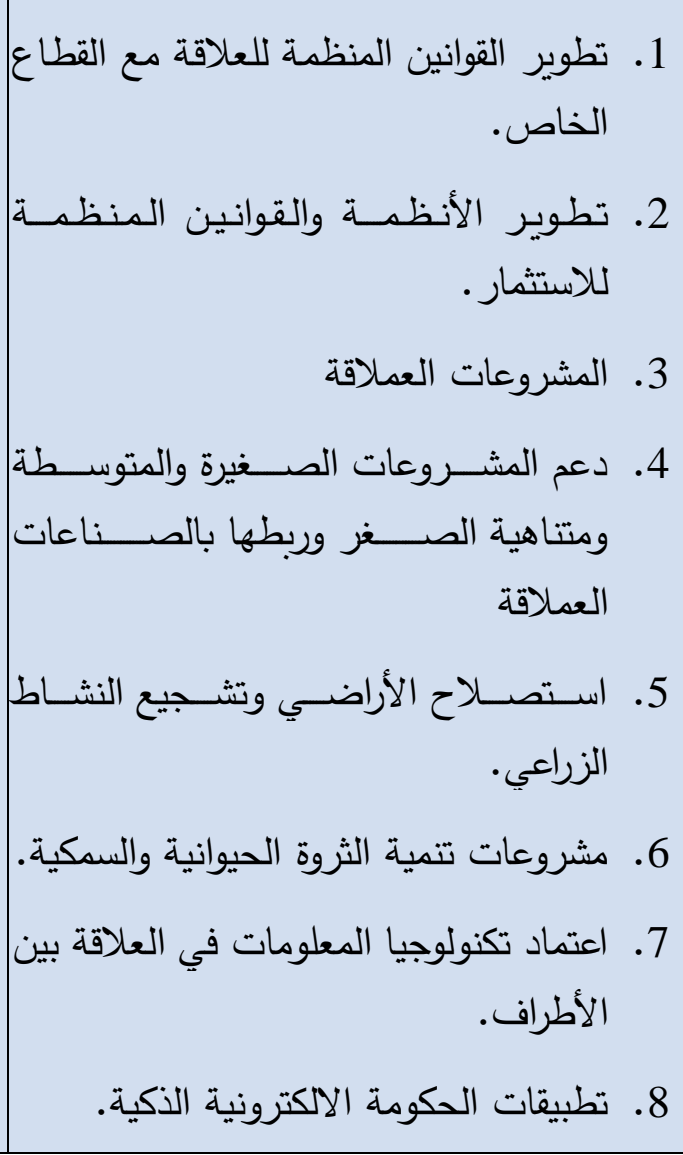 & 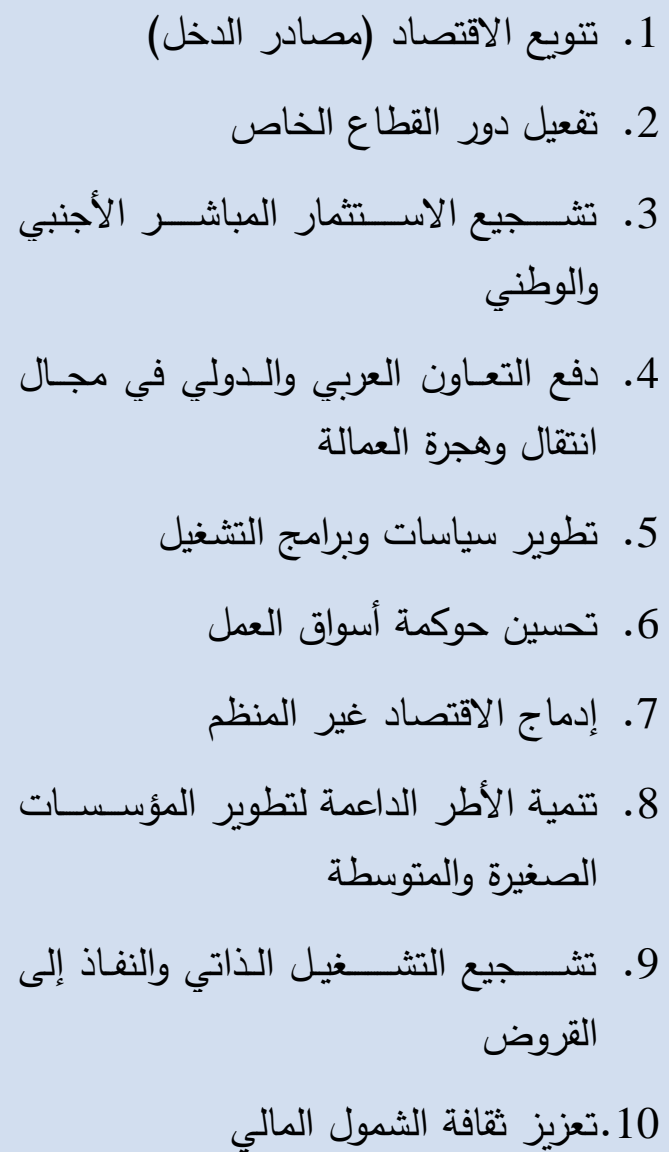 & 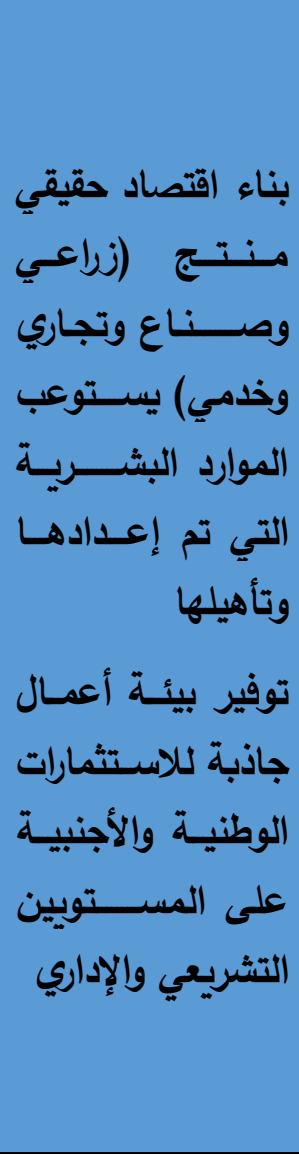 \\
\hline
\end{tabular}


ثالثاً: تحديات إعادة الإعمار في الدول التي شهدت صر اعات وثور ات داخلية.

\begin{tabular}{|c|c|c|c|}
\hline مؤشرات الأداء & البرامج & المبادرات & الههف الاستراتيجي \\
\hline 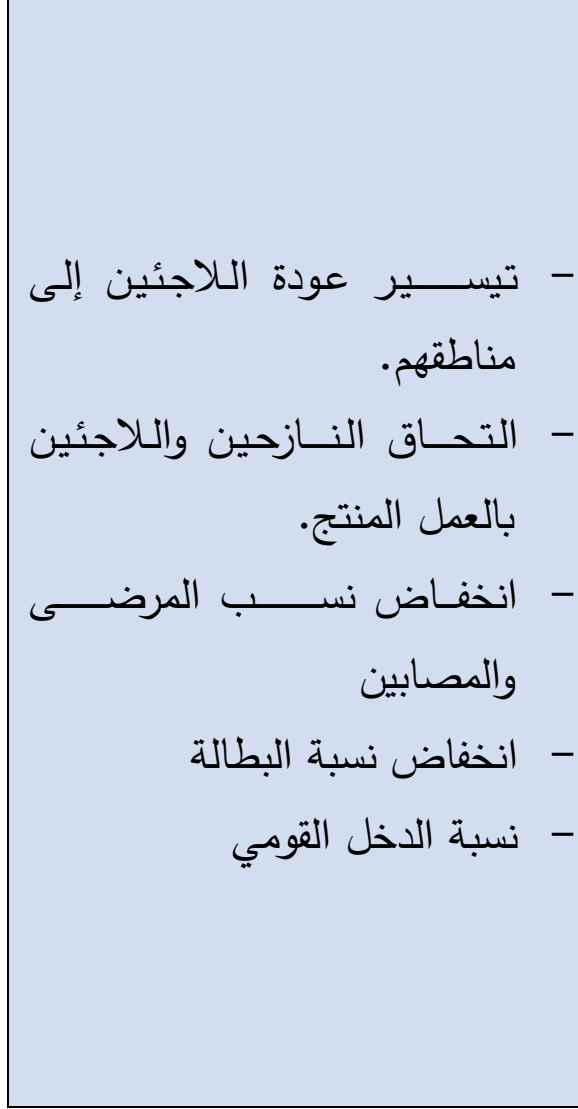 & 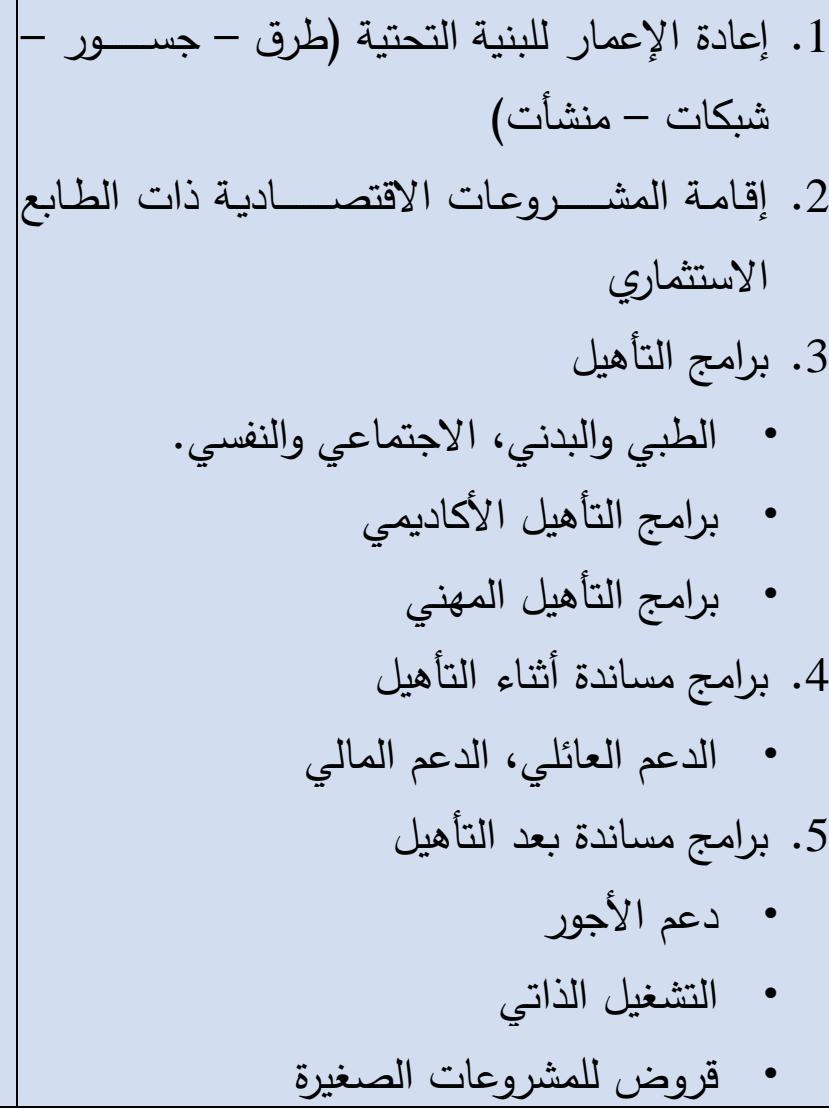 & 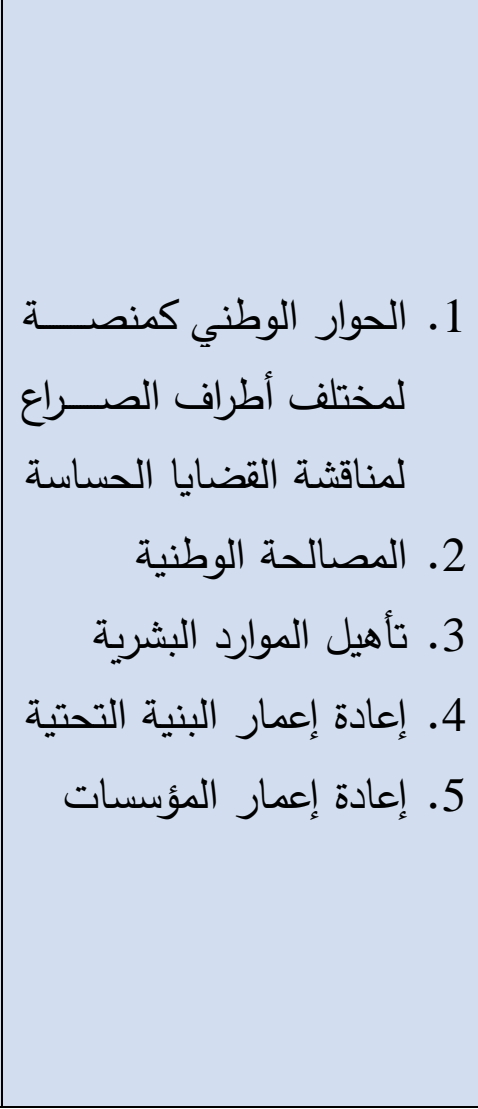 & 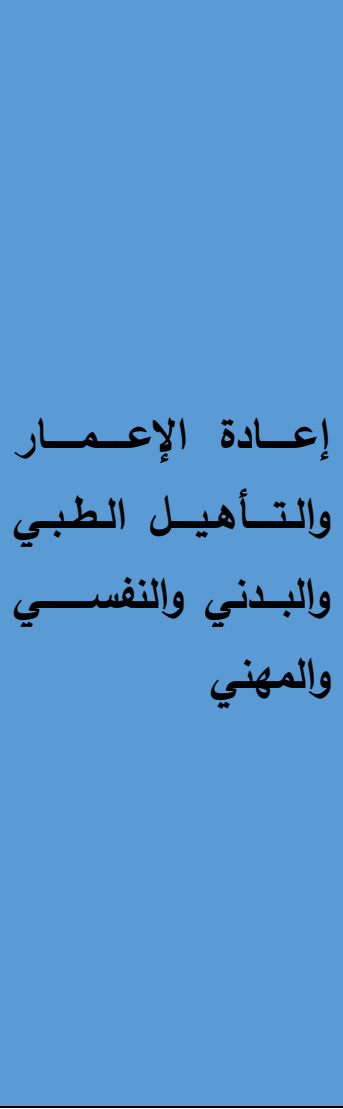 \\
\hline
\end{tabular}


ومهما يكن من أمر في شأن تلك المبادرات السابق عرضها، نود أن نعرض لرؤية استراتيجية

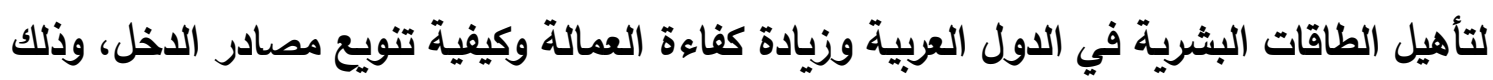

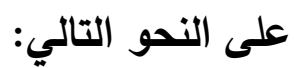
أ. قيام الدول العربية بتأسيس هيكل يضم الوزارات والإدارات الحكومية، وممثلي أصحاب الأعمال والمنظمات العمالية لترتيب الأولويات والخيارات الاستراتيجية للتخطيط وتمويل التدريب، حتى يصبح القطاع الصناعي المتطور أكثر قدرة على المنافسة في الأسواق المحلية

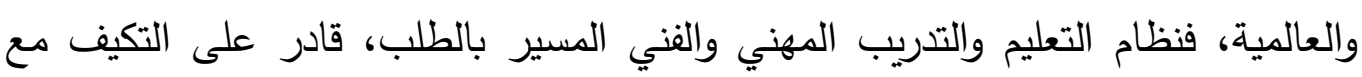
متطلبات تحديث قطاعات الصناعة والقطاعات ذات الصلة حيث من المفترض ولن أن يشمل المبادئ التالية:

1. تعزيز قدرة أنظمة التعليم والتنريب على المنافسة:

- الإسراع بتطبيق إصلاح التعليم الإساس لتتمية قاعدة تعليمية صلبة.

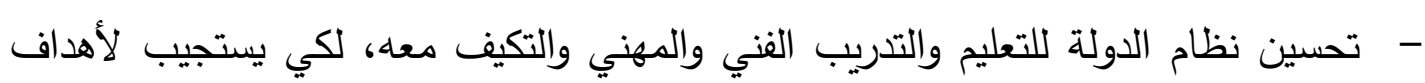
قطاع الصناعة المتعلقة بقدرته على المنافسة والنمو.

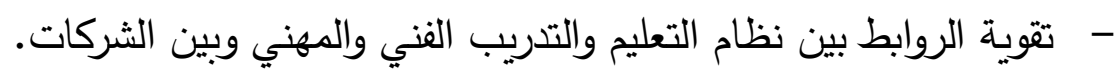
2. (1) - مقد المشاركات: - - إن تأسيس التحالفات التدريبية غاية في حد ذاته إضافة إلى كونه أداة سياسية مهمة لتحريك

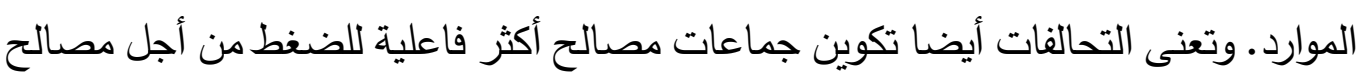

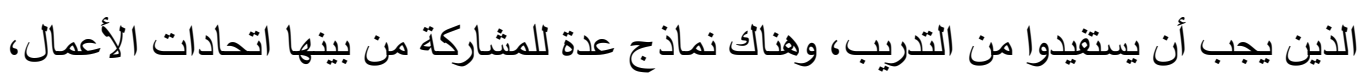
واتحادات أصحاب الأعمال، واتحادات المستثمرين بالوحدات الإقليمية، وتعاونيات المنتجين،

$$
\text { واتحادات العمال....إلخ. }
$$

- - يضمن إسهام الشركات في اتخاذ القرار انعكاس طلباتها على برامج التدريب ويمكن استخدام

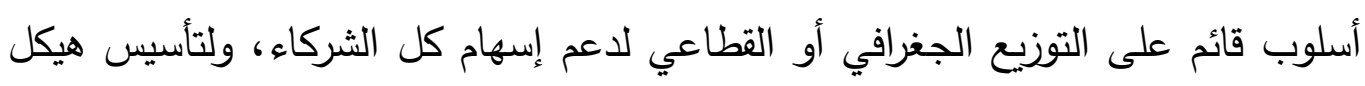
مناسب، ولتتبنى المعايير المهنية الملائمة.

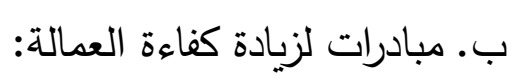

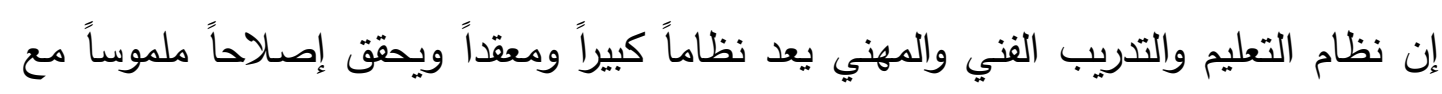
الوقت فالبرنامج الثامل المصمم لتلبية المهارات المطلوبة لتحديث الصناعة هدف مزدوجي: 
التعليم والتدريب السابق للتوظيف: تسهيل التنمية وفق طلبات قطاع الصناعة والقطاعات ذات الصلة ولتمهيد الطريق أمام نظام يميل للتنافسية. التدريب اللاحق للتوظيف: تعزيز إسهام أكبر من قطاع الصناعة في التدريب لتلبية احتياجاته، ليشمل معايير بعيدة المدى ومبادرات فورية من المنتظر أن تأتى بنتائج ملموسة فئس في المدى القصير والمتوسط. ج. تتمية آليات بديلة للتنمية لتويع مصادر الدخل 1. يعد تتويع مصادر التمويل هدفاً للوصول إلى مشاركة عادلة ودائمة فى تكاليف برامج التدريب ذات الصلة، ويتطلب ذلك تبنى سياسات جديدة لتتمية الموارد وتطبيق آليات تمويل نظام التعليم والتدريب ويعتمد ذلك على: م أن يكون نظام التتريب على المنافسة. ان يتم تقييم النتائج بانتظام عن طريق نظام إدارة للتدريب ذي كفاءة عالية. 2. يعتبر إنشاء صندوق للتدريب خياراً استراتيجيا لدعم نظامي التعليم والتدريب الفني والمهني. 3. ويمول الصندوق، التدريب السابق واللاحق للتوظيف، بناء على معايير محددة سلفاً ومعدة

$$
\text { بالاثتراك مع قطاع الصناعة. }
$$

4. ويمول صندوق التدريب بهبات من الحكومة والمانحين.

\section{ونود في ختام هذا المبحث ان نؤكد على الملاحظات التالية:}

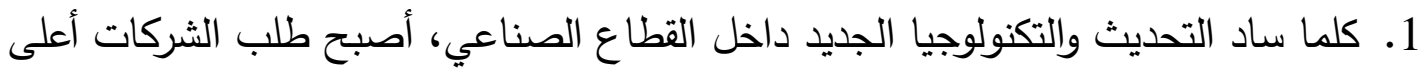

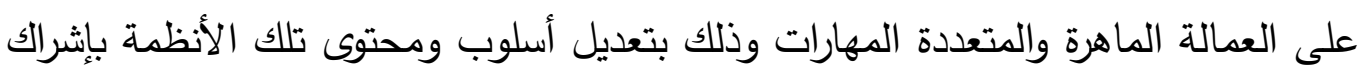

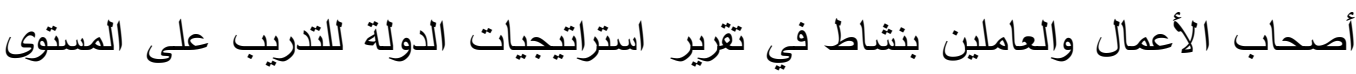
القومي ومستوى القطاع الصناعي. 2. هناك فرصة سانحة لتتمية برامج تركز على السياسة القومية بعيدة المدى، والمشاركات التدريبية، ونظام اعتماد وملاءمة البرامج، وآليات تمويل جديدة فتتمية برنامج تدريب وتعليم فني ومهني على هذا النحو سيضمن التكامل بين جهود التحديث. 


$$
\text { المبحث الرابع }
$$

دور الحكومات العربية و القطاع الخاص وصناديق التنمية العربية في رسم وتنفيذ تلك الاستر اتيجيات

قبل أن نعرض دور الحكومات العربية والقطاع الخاص وصناديق التنمية العربية في رسم

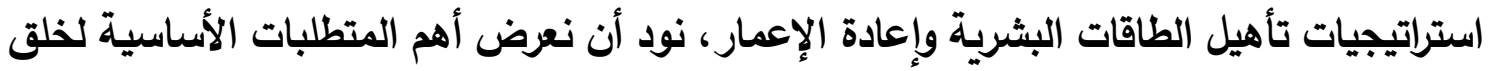
المناخ المناسب لتأهيل الطاقات البشرية وضمنا الاستفادة منها: استعادة الأمن واستقرار الأوضاع السياسي. إعادة دمج الميليشيات والمحاربين السابقين والثباب والنساء.

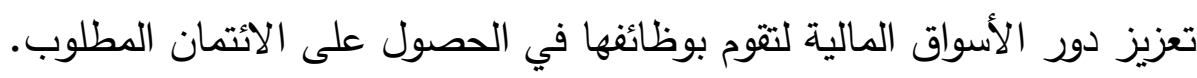
تهيئة الأطر القانونية لتشجيع الأعمال. إعادة هيكلة مؤسسات القطاع العام. بناء مهارات تتافسية من أجل القطاعات الناشئة وريادة الأعمال الحرة. • تعزيز التدريب العملي الداخلي وبناء قدرات وكفاءات في شتى القطاعات الاقتصادية.

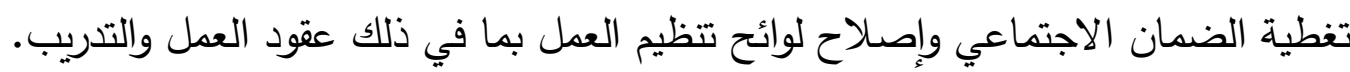

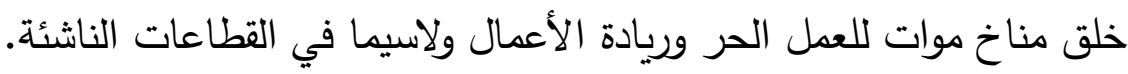

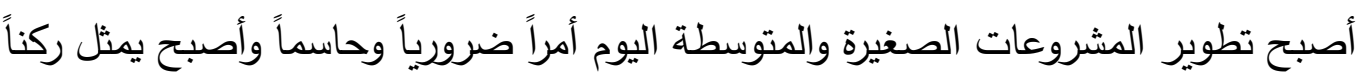

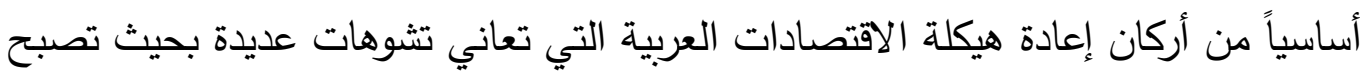

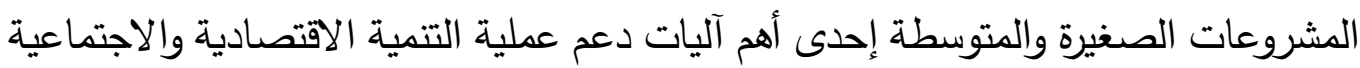
والبشرية، ومحاربة البطالة في وطننا العربي وبخاصة بعد إخفاق معظم الإجراءات والسياسات السابقة.

تعزيز مبدأ الثمول المالي لكي يطال شرائح المجتمع كافة. وسنعرض في هذا المبحث للنقاط التالية:

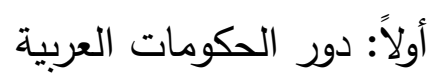

ثانياً: دور المنظمات العربية المتخصصة - المنبثقة عن جامعة الدول العربية

$$
\text { ثالثاً: دور القطاع الخاصاً: دور المنظمات التربية التاد }
$$


أولاً: دور الحكومات العربية(17)

يتلخص دور الحكومات العربية في تأهيل الطاقات البشرية وإعادة الإعمار في المحاور التالية: 1. توفير بيئة تشـــريعية ملائمة وقوانين ونظم خدمة مدنية او وظيفة عامة، وقوانين عمل، تكفل لإدارات الموارد البشـرية بالمؤسـسـات الانتاجية "السـلعية أو الخدمية" الحكومية والخاصـة، أن تمارس دورها كادارات موارد بشـرية اســتراتيجية، تشــارك في تحقيق أهداف التتمية الثــاملة للدولة.

2. توفير الأطر المؤســســـية "كوزارات الخدمة المدنية، أجهزة التظظيم والإدارة" على تفعيل دور إدارات الموارد البشرية الاستراتيجية ونهوضها بوظائفها الأساسية، التي تسهم في تحقيق أهداف المؤســـــــات الحكومية، وتتمثل هذه الوظائف في (التخطيط الوظيفي - الإدارة الوظيفية التطوير الوظيفي - الدعم الوظيفي). 3. تبني برامج وطنية لإصلاح وتطوير منظومة التعليم بكافة مراحله ومستوياته، مع التركيز على: - التعليم الأسـاسي (من 3 - 12 سنة) باعتبارها مرحلة حاسمة يتعين أن تؤخذ في الاعتبار لتحقيق تتمية بشرية حقيقية. - ـ التعليم الفني والمهني والتقني بما يحقق المواءمـة بين مخرجات التعليم الأكاديمي والمهني والحاجات التنموية ومتطلبات سوق العمل. - عديل سياسات ونظم القبول بالتعليم العالي استرشاداً بالتجارب العالمية في هذا المجال. - تثجيع البحث العلمي ودعم الباحثين والمبادرين وزيادة المخصصات المالية لهذا النشاط. 4. تهيئة بيئة أعمال مناســبـة وآمنة، جاذبة للقطاع الخاص وللاســـتثمارات الوطنية والأجنبية واسـتقطاب شـركات اســتثمارية عالمية ذات قدرات اقتصــادية وتقنية جيدة في مجال النفط والتعدين وإنشاء البنى التحتية كالطرق والكباري وشبكات الكهرباء والمياه والصرف والمجمعات السـكنية لتتهض بمسـؤولية الإعمار وتسـهم في ذات الوقت في تأهيل الطاقات البشـرية وخلق فرص عمل تســاهم في الحد من مشــكلة البطالة (على غرار تجربة شــركة أرامكو بالمملكة العربية السعودية).

5. إصــــلاح نظم الخدمة المدنية، وعلاج مشـــكلات التضـــــم الإداري والوظيفي في الجهاز الحكومي، وتفعيل دور إدارات الموارد البثـــريـة بالمؤســــــــات الحكومية، واتخاذ إجراءات استراتيجية متكاملة للتصدي للفساد الإداري. (17) التقرير المتامي لمؤتمر مؤسسة الفكر العربي، فكر 15، 2016. 
6. ضــرورة وضـع خطط وطنية واسـتراتيجيات منهجية متكاملة وهادفة إلى رفع الطاقات الخلاقة لدى الثـــباب العربي والقوى العاملة لخفض معدلات البطالة وتوفير الكوادر الكفؤة والمبدعة والتركيز على تبنى مبادرات وبرامج تثـغيل الثـباب في القطاعات الاقتصـادية الأكثر دينامية

$$
\text { والمؤهلة بشكل أكبر للاستفادة من طاقات الثباب العربي: }
$$

7. توفير برامج الحوافز لدعم التدريب والتأهيل وذلك من خلال التعاون بين الحكومـة والقطاع الخاص وحفز الشباب على التقدم للتدريب والتأهيل واكتساب الخبرات المهنية، وفتح المؤسسات الإنتاجية العامة والخاصة أمام الشباب للتدريب. 8. توفير التعليم والتأهيل والتدريب لذوي الاحتياجات الخاصـــــة وبما يتتاســــبـ وقدراتهم العقلية والجسدية ودمجهم في سوق العمل. 9. برامج الإعانات المالية للأجور والتشـغيل وذلك بتقديم الإعانات المالية للمؤسـسـات والمعاهد والثـركات والمصـانع التي تقوم بتدريب أو شـغيل عدد من العاطلين عن العمل أو ذوي الخبرة في مهن وصناعات وقطاعات معينة. 10. العمل على إقامة الحاضنات التكنولوجية ومنصات المعرفة. 11. الاســتعانة بالخبرات والتجارب الأجنبية والمدربين الأجانب ونقل الخبرات والبرامج التدربيية في المجالات المختلفة ولاسيما في المهن المتخصصة وذلك التي تحتاج إلى التكنولوجيا المتقدمة. 12. التعاون ما بين الجامعات والمعاهد التطبيقية والمدارس الصـــنـاعية لتدريب الطلاب الذين يحتاجون إلى التدريب والذين تتطلب مســاقاتهم وتخصــصــاتهم التدريب والتأهيل، وهم على مقاعد الدراسة في مؤسسات وشركات القطاع الخاص. 13. العمل على تخفيف حدة ثقافة العيب في بعض الدول العربية من العمل المهني أو الحرفي أو في الزراعة أو غيرها من المهن والتي تشــلها العمالة الأجنبية الوافدة من جنوب وجنوب شـرق آسيا، من خلال حملات التوعية بقدسية العمل واكتساب المهارات المهنية والحرفية. 14. التعاون مع المنظمات الدولية والإقليمية ذات الاهتمام بتخفيف البطالة بالتدريب والتأهيل للقوى العاملة وتدريب المدربين والاسـتفادة من المسـاعدات المالية والفنية التي تقدمها هذه المنظمات

$$
\text { للحكومات والقطاع الخاص في هذا الشأن. }
$$

15. إنشاء صندوق عربي للتنمية البشرية تسهم فيه جميع الدول العربية كمنظمة عربية مستقلة تقوم بتمويل تدريب وتأهيل الطاقات العربية في جميع القطاعات وعلى جميع المســـــــات الإدارية 


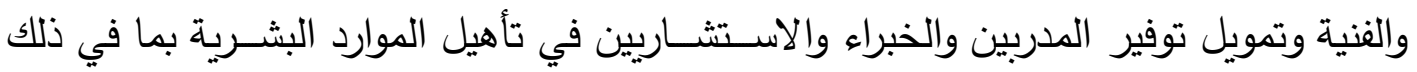
توفير القيادات الإدارية والفنية لجميع المؤسسات في جميع القطاعات.

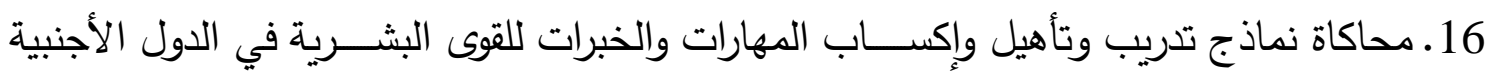

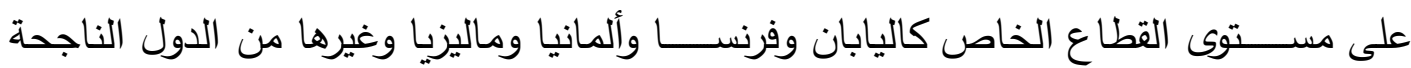
والمتميزة في هذا المجال. الماع. 17. العمل بكل الوســائل والسـياسـات الحكومية لتثـــيع القطاع الخاص للاسـتثمار في التعليم والتدريب المهني والتقني. 18. دعوة الحكومات العربية للقطاع الخاص بالمشاركة الاستثمارية الإنتاجية في مؤسسات التعليم والتدريب المهني والتقني.

ثانياً: دور المنظمات العربية المتخصصة ـ المنبثقة عن جامعة الدول العربية(18)

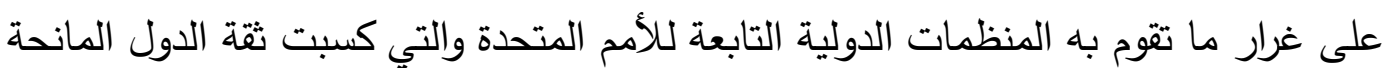
والممولة لبرامج مواجهة العنف والصراعات وإغاثة وإيواء اللاجئين، بالإضافة إلى برامج بناء القدرات

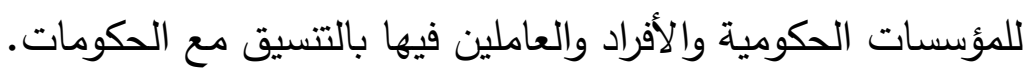

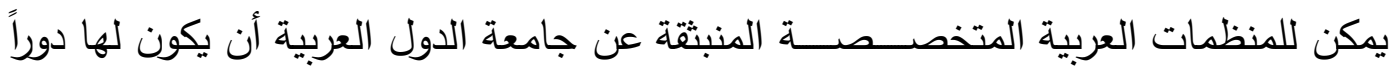

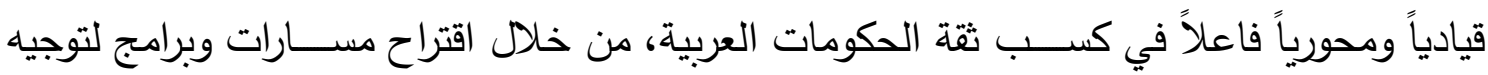

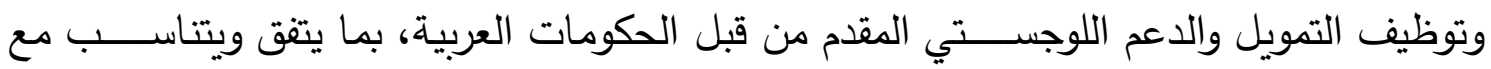

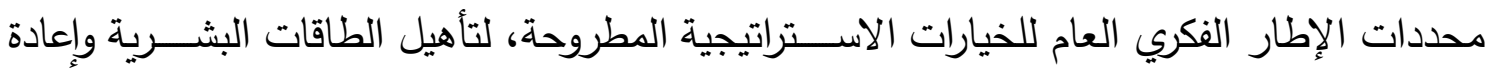

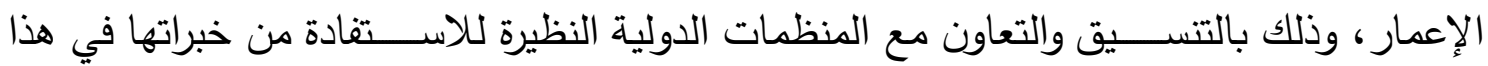

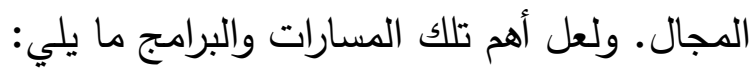
1. برامج إغاثة وإيواء اللاجئين والنازحين بدعم مخيمات اللاجئين وتوفير المستلزمات المعيشية.

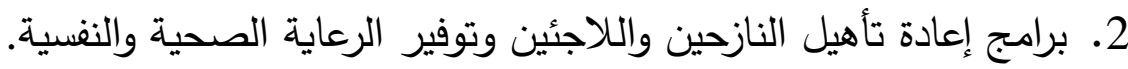
3. برامج تطوير قدرات الأفراد وإعادة تأهيلهم نفسياً واجتماعياً. 4. برامج تعزيز المواطنة والبناء القيمي 5. برامج تستهدف التقارب العربي الفكري وتثجيع البحث العلمي والإبداع والابتكار

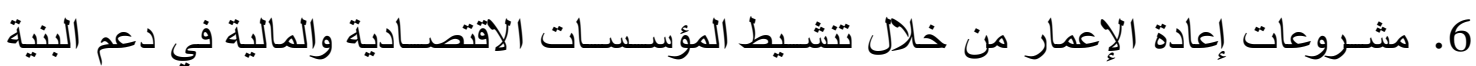
التحتية 


$$
\text { 7 ثالثاً: دور القطاع الخاص الحوكمة وتشجيع تبادل الخبرات العربية }
$$

يعد القطاع الخاص العربي داعماً رئيسياً للتمية الاقتصادية العربية، فهو الممول الأكبر

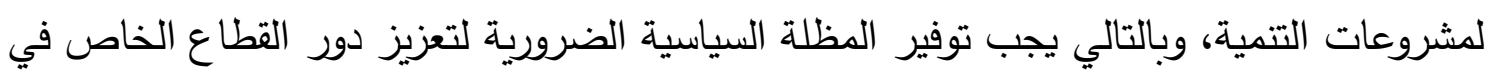

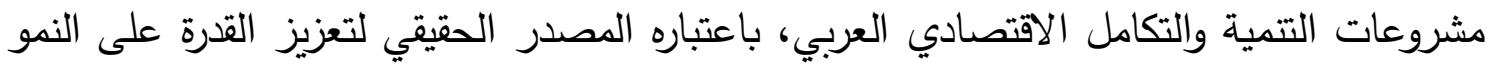

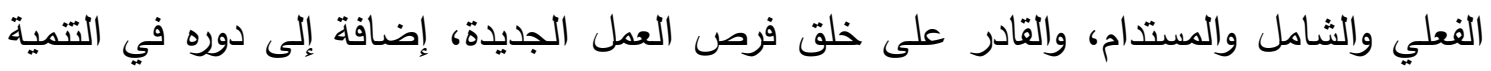
الاقتصادية والاجتماعية من خلال المسؤولية الاجتماعية الملقاة على عاتقه، وهو الممول المالفي الأكبر

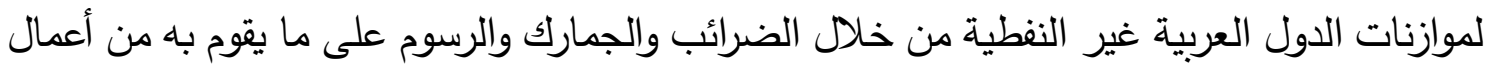
ويحققه من أرباح.

ويمكن تلخيص دور القطاع الخاص في النقاط التالية: 1. رفع مستوى وتأهيل وتدريب الطاقات العربية:

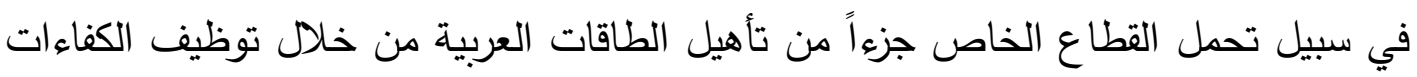

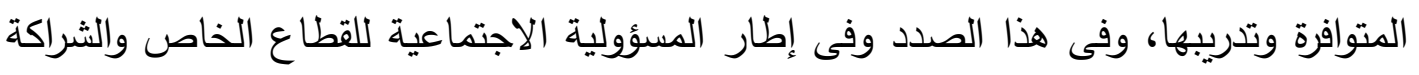
بين القطاعين العام والخاص يمكن أن يرفع القطاع الخاص مساهيته في تأهيل الطاقات العربية من خلال ما يلي: 2. تدريب طلاب الجامعات والمعاهد ومراكز التأهيل المهني والمعاهد التطبيقية والمدارس الصناعية

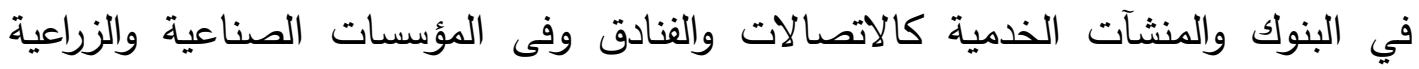

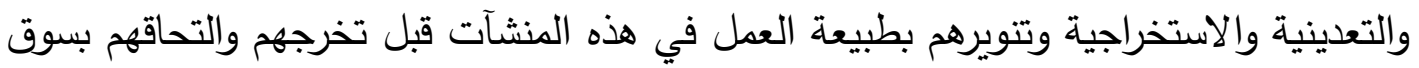

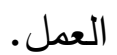

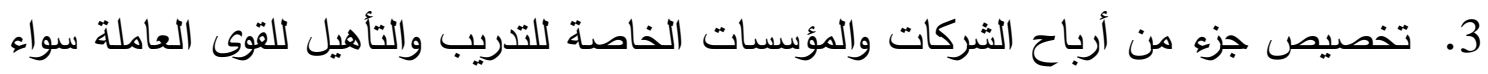

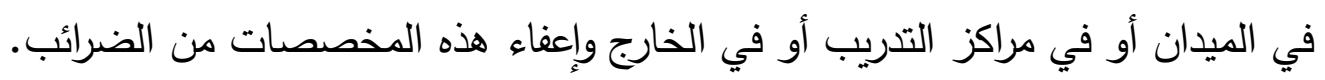

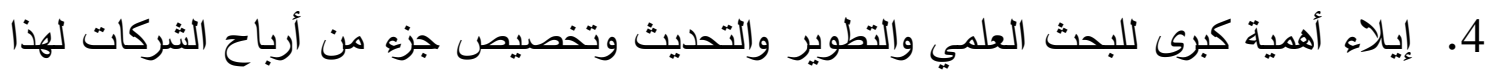

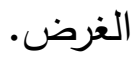
5. تضصيص مقاعد في الجامعات للمتميزين والمبدعين للحصول على التعليم الجامعي بمراحله كافة وخصوصا التعليم العالي المتخصص وتمويلها من الشركات. 6. مشاركة القطاع الخاص في برامج التأهيل والتدريب وإكساب المهارات للقوى العاملة والباحثين عن العمل وتقييم فاعلية تلك البرامج وتواؤمها مع احتياجات سوق العمل. 
7. توسيع نطاق الطاقة الاستيعابية في المدارس الثانوية والمعاهد الفنية الخاضعة للقطاع الخاص

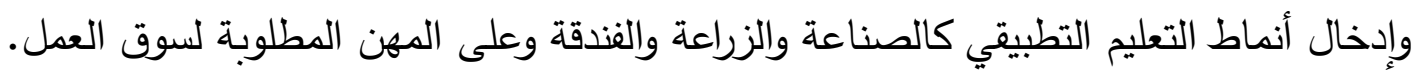
8. تطويع علوم النانو وتتنياته وتعزيز الوعي بأهمية الاستيعاب والتحكم في تطبيقات النانو وتأثيراتها

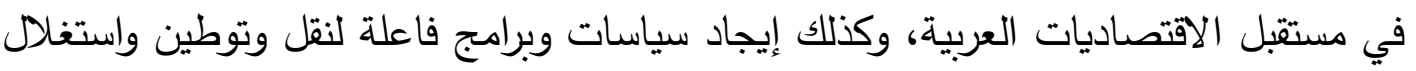
أمثل لعلوم وتقنيات النانو في المنطقة العربية.

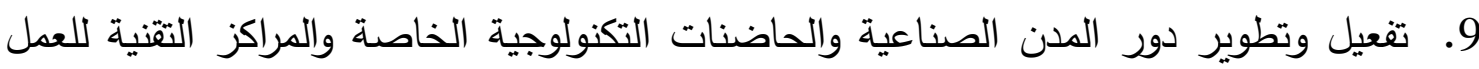

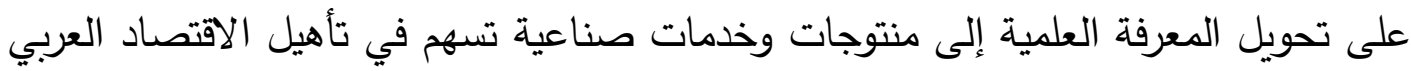
للاندماج في الاقتصاد العالمي.

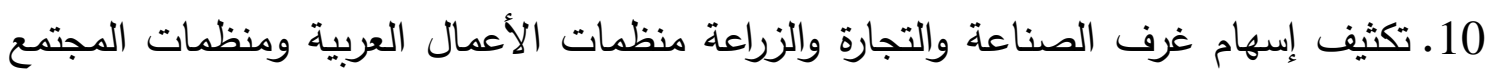
المدني ذات العلاقة بتدريب الكوادر الإدارية والفنية العاملة في مؤسسات القطاع الخاص التاص

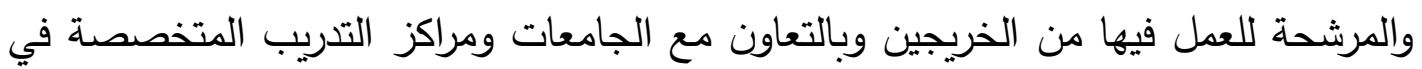

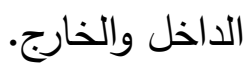
11. على النقابات والجمعيات المهنية والاتحادات العمالية ومنظمات المجتمع المدني أن تركز على

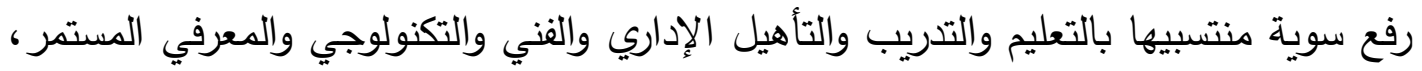

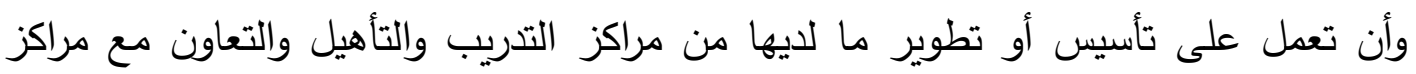

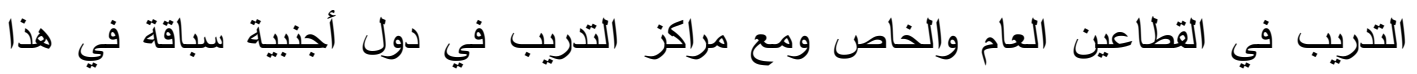

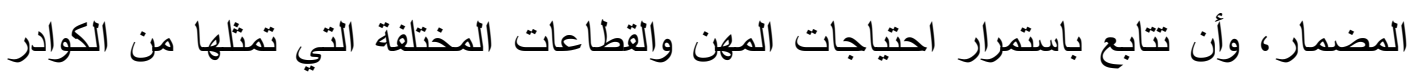

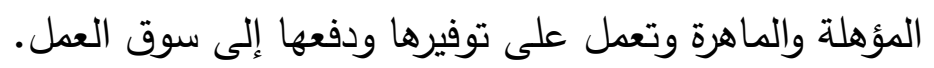

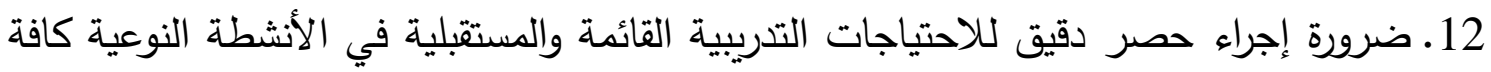

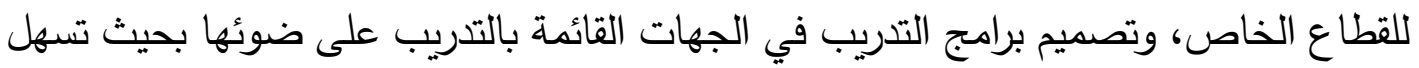

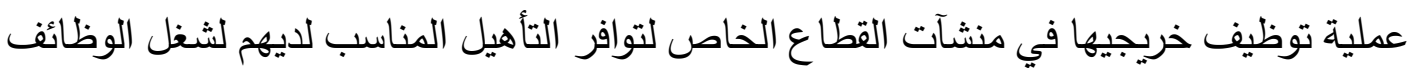

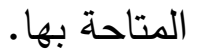
13. قيام الجهات ذات العلاقة بوضع خطة استراتيجية شاملة لتنمية القوى البشرية، تشمل مرتكزات

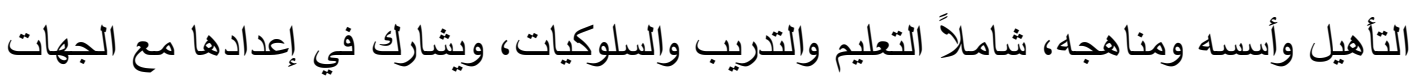

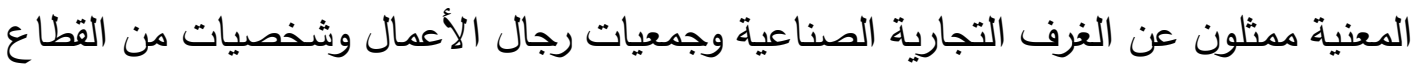

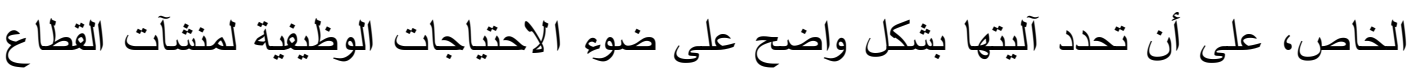
الخاص وتوصيف الوظائف بها. 14. إنشاء صندوق تعويضي (offset fund) في كل دولة عربية يمول من مبالغ تقتطع من أرباح 
الشركات وتنزل من الأرباح الخاضعة للضريبة، ويخصص الإنفاق من الصندوق للبحث

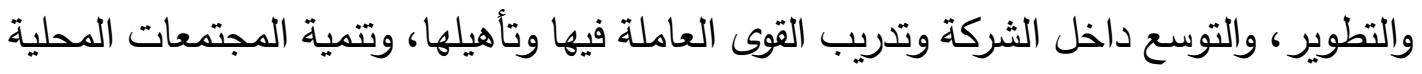

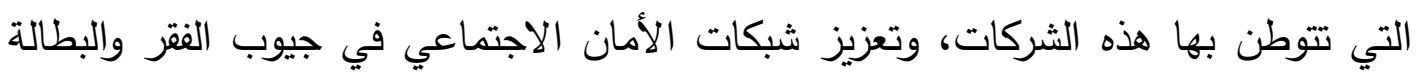

$$
\text { وبالذات الوضع الصحي والتعليمي. }
$$

15. محاكاة نماذج تدريب وتأهيل وإكساب المهارات والخبرات للقوى البشرية في الدول الأجنبية على والي

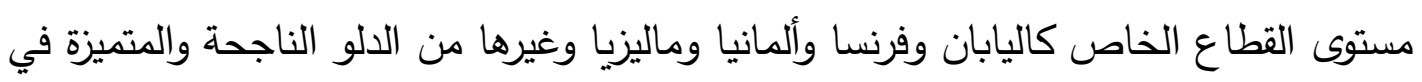

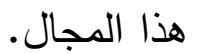

16. مساهمة رجال الأعمال والمستثرين العرب في دعم الاقتصادات العربية وتعزيزها من خلال

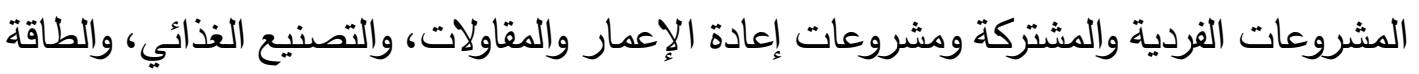

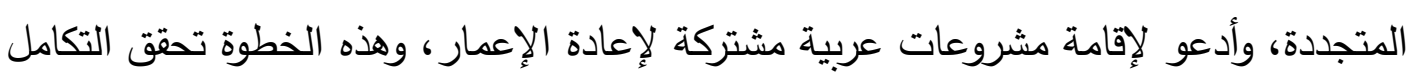
الاقتصادي الذي نسعى لتحقيقه. 17. مساهمة الجهاز المصرفي والمالي العربي في التتمية والإعمار حيث إن القطاع الدصرفي العربي

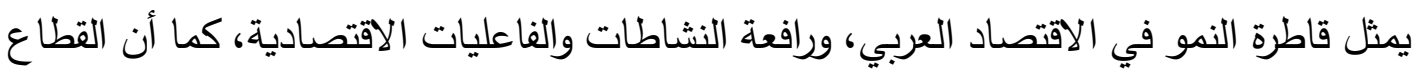

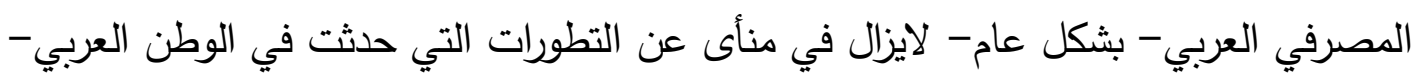

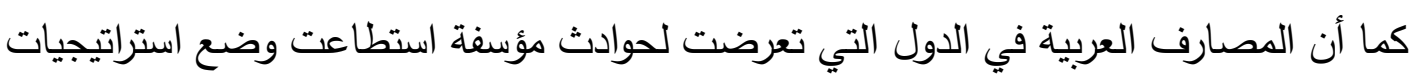
مكنتها من التأقلم مع الأوضاع المستجدة، ويعتبر القطاع المصرف التصرفي العربي ركيزة للإعمار

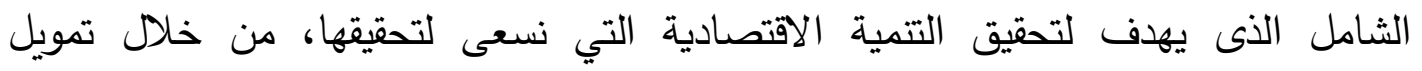
المشروعات العامة والخاصة بالقروض والتسهيلات المناسبة. 18.تخصيص نسبة من أرباح مؤسسات وشركات القطاع الخاص للبحث العلمي والتطوير التكنولوجي، وتمويل برامج التدريب المستمرة للقوى البشرية العاملة فيها.

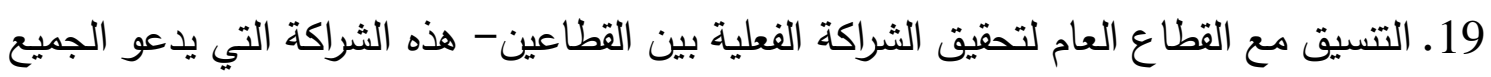
لها، ونريدها أن تتحقق وعلى أرض الواقع. 20. التثاور وإبداء الرأي في التشريعات التي تعدها الحكومة والتي تتعلق بالثؤون الاقتصادية والمالية التي تخدم قضايا التتمية البشرية. رابعاً: دور صناديق التمويل العربية

أ. بعض مبادرات صناديق التنمية العربية: تتميز المنطقة العربية بوجود عشرة صناديق تتمية اقتصادية واجتماعية إقليمية ووطنية اكتسبت

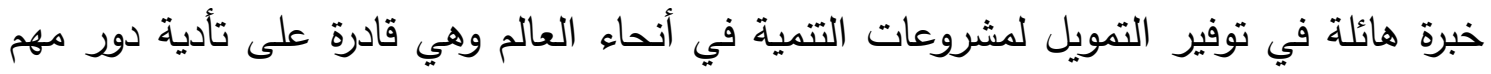

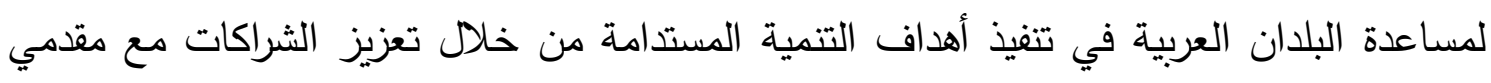


التمويل التتموي الآخرين مثل الحكومات العربية والقطاع الخاص ونذكر على سبيل المثال لا الحصر

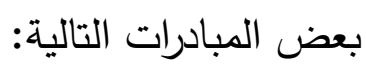
مارس 2016: إطلاق مبادرة البنك الإسلامي للتنمية "من أجل الإسهام في إتاحة فرص التعليم

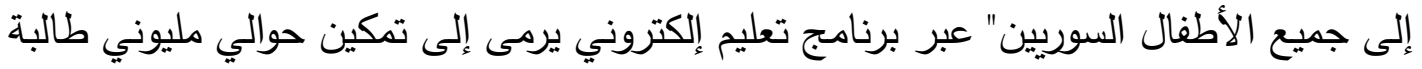

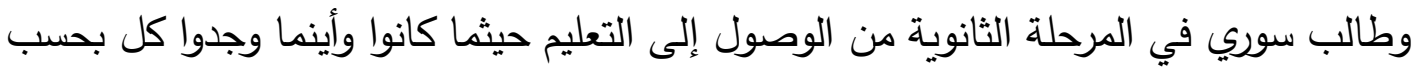

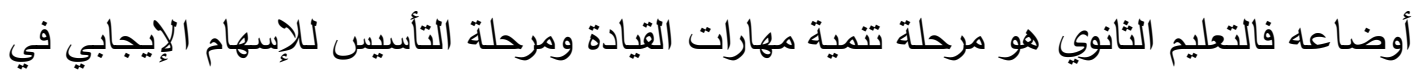
بناء المجتمع وفى إعادة الإعمار بعد النزاع.

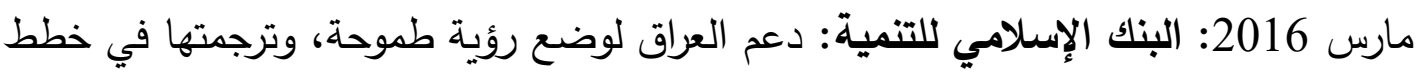

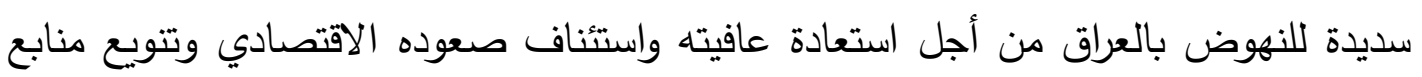

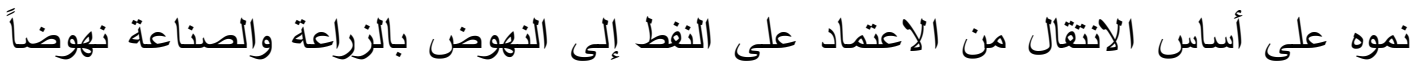

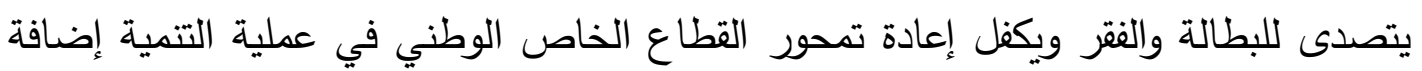

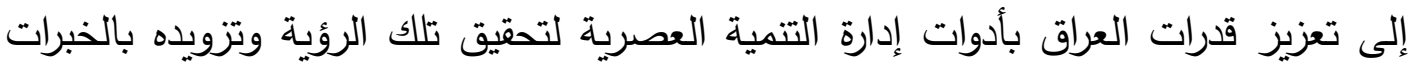

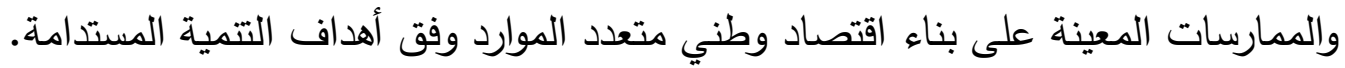

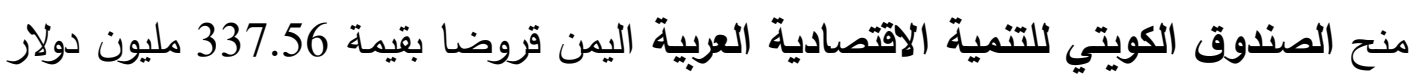
لتمويل 8 مشروعات تتموية في اليمن منذ العام 2009. الصندوق الاجتماعي للتنمية في اليمن: تنفيذ وإنجاز حوالي 4 آلاف مشروع لتبن بتكلفة تعاقدية

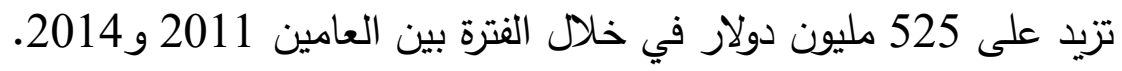

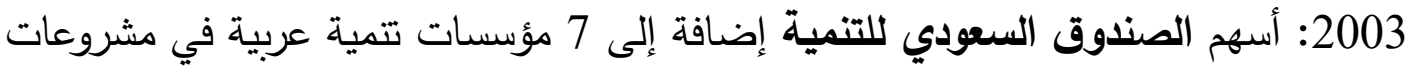

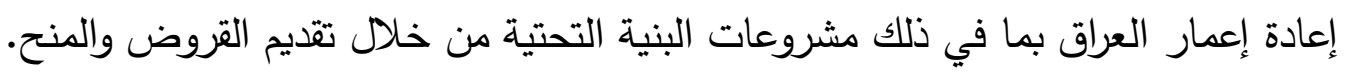

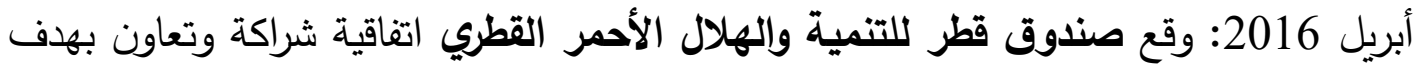
تنفيذ مجموعة من التنخلات الإنسانية العاجلة لإغاثة المحاصرين والنازحين العراقيين في فضاء

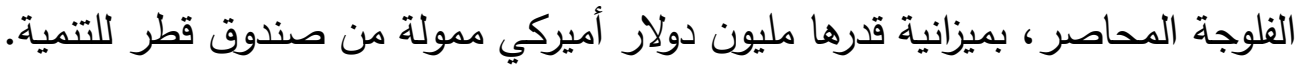

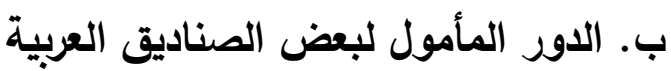

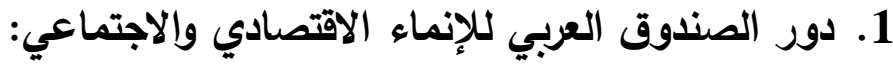

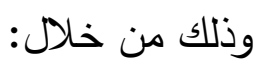

تمويل المشروعات الاقتصادية ذات الطابع الاستثماري والتي تسهم في ذات الوقت في بناء

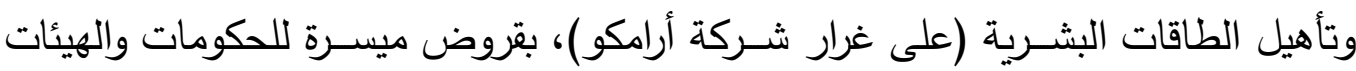

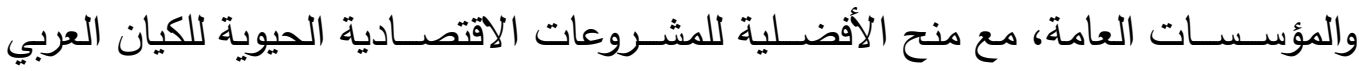


وللمشـاريع العربية المشـتركة، والتي تسـتوعب الطاقات البشـرية المؤهلة بما يسـهم في حل

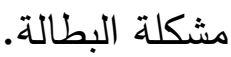
تمويل مشـاريع القطاع الخاص عن طريق تقديم القروض والضمانات على اختلاف أنواعها للمؤسـسـات والمنشـآت ذات الثـخصـية الاعتبارية والمســاهمة في رؤوس أموالها وتوفير عمليات التمويل الأخرى والخدمات المالية والفنية والاستشارية اللازمة لهذه المشارية والثاتيع.

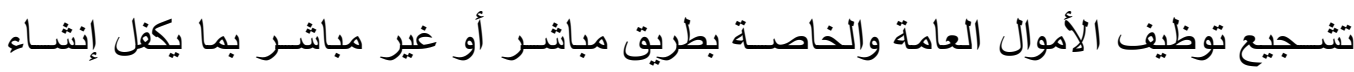
معاهد ومراكز تدريب وتأهيل تقني وفني وفقاً للمعايير العالمية. توفير الخبرات والمعونات الفنية في مختلف مجالات تأهيل الطاقات البشرية.

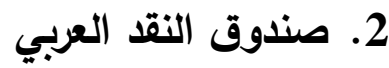
وذلك من خلال المساهمة فيما يلي: إرساء السياسات واساليب التعاون النقدي العربي. تطوير الأسواق المالية العربية، وتهيئة الظروف المؤدية الى انشاء عملة عربية موحدة.

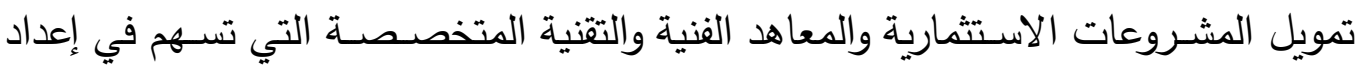
وتأهيل الطاقات البشرية بالدول العربية.

3. الصناديق القُطرية

الصندوق الكويتي للتنمية. صندوق أبوظبي للتنمية.

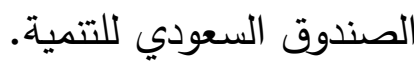

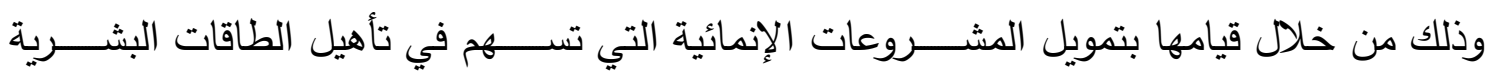

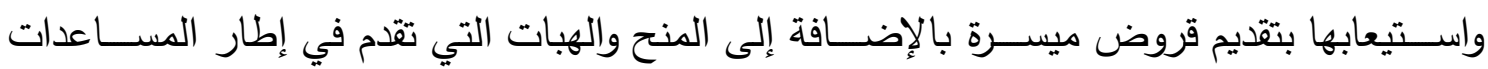

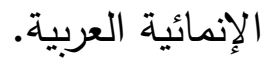




\section{الخلاصة و التو صبات}

رغم تزايد الإنفاق على التعليم وتأهيل الطاقات البشـرية، إلا أن الإنجازات في نوعية التعليم

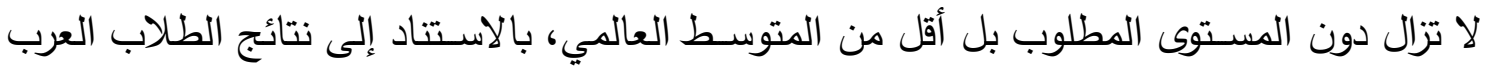
في المناظرات الدولية في العلوم والرياضيات. فلم تحقق برامج إصلاح التعليم نجاحات ملحوظة في إكسـاب الطلبة المهارات والمعارف والقدرات المطلوبة لزيادة الإنتاجية وخلق ميزات تنافسـية جديدة تعتمد على التجديد والابتكار في ظل الموارد المحدودة والطلب المتزايد على خدمات التعليم وتفوق الأهداف الكمية في سلم الأولويات على حساب نوعية التعليم، والتأثير السلبي على مستوى الطاقات البشرية وانعكاسه على زيادة نسب البطالة.

ونظراً لعدم تتوع الاقتصادات العربية بحكم نموذج التنمية الذي كان سائدًا، وبحكم التشوهات

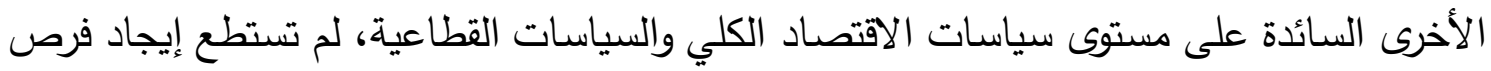

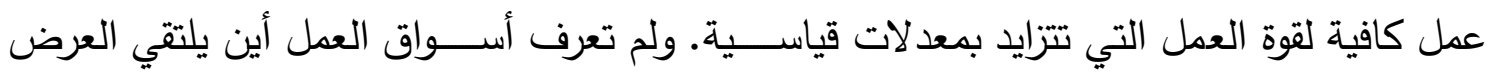
والطلب لتعمل بكفاءة في ظل غياب المعلومات ونقص آليات الاتصــــال بين الباحثين عن عمل

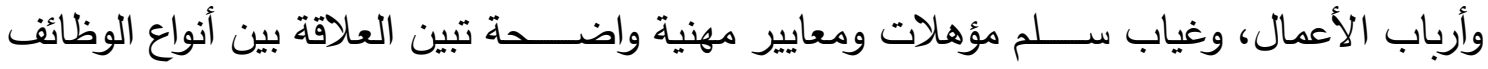

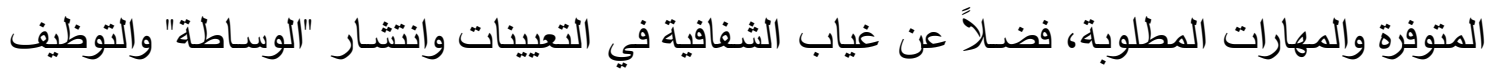
من خلال العلاقات الشخصية.

وفي ظل التحديات الســـابقة، تم تقديم بعض الاســـتراتيجيات والمبادرات والبرامج التي من

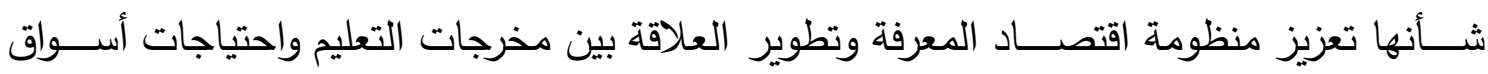
العمل. ومكافحة ظاهرة البطالة، تتلخص فيما يلي: أولاً: تطوير دور المنظومة التعليمية في تحسـين آفاق التشـغيل للخريجين، مع تفعيل دور إدارات

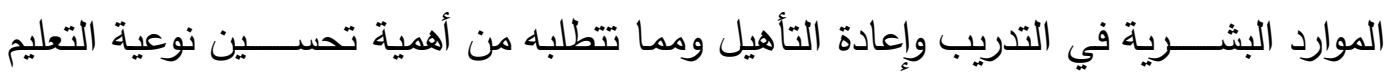
والنهوض بالمناهج، وتفعيل دور الحكومات العربية في منظومة اكتـــــاب المعرفة، وإعادة النظر في سياسات وآليات تمويل التعليم العالي، وكذلك تفعيل دور الجامعة في تحسين آفاق تشـغيل خريجيها والتحول من منطق إنتاج الثـهادات إلى منطق إنتاج المهارات، ومن منطق

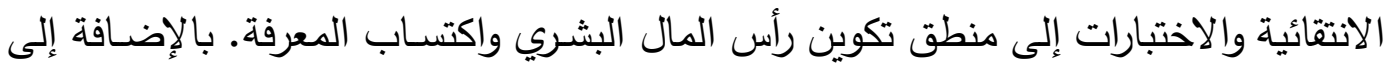

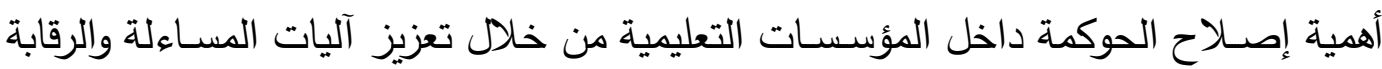

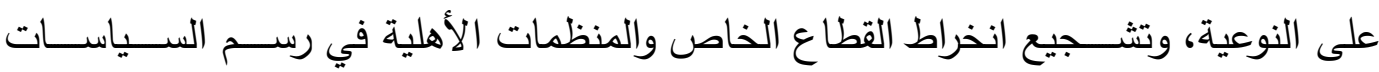
التعليميـة، وتقديم الحوافز اللازمـة لكل الأطراف المعنيـة لزيـادة التوافق بين مخرجات لتعليم العالي واحتياجات أسواق العمل. هذا بالإضـافة إلى تعزيز المســاءلة بناءً على الأداء والتقييم وبناء الأطر الملائمة لضــمان الجودة سـيما من خلال مؤسسـات ولجان محايدة ومستقلة عن المؤسسـات التي يتم تقييمها. 
فضلاً عن تقليص الهوة بين مخرجات التعليم ومتطلبات أسواق العمل، وتثجيع التعليم الفني

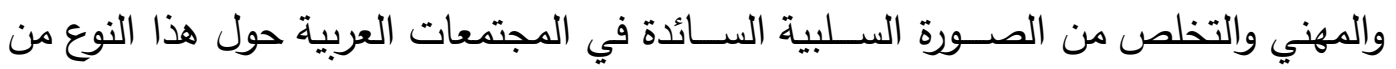

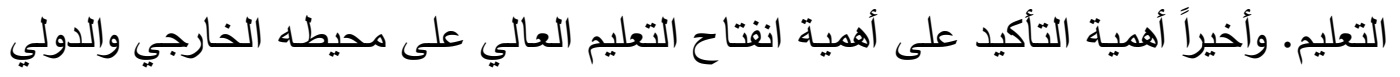

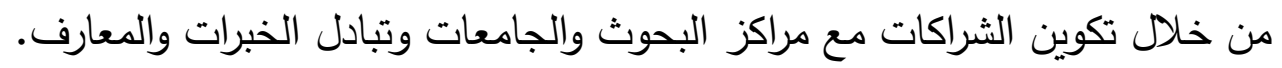

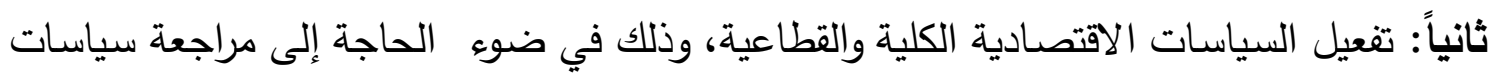

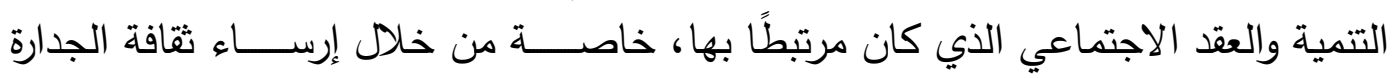

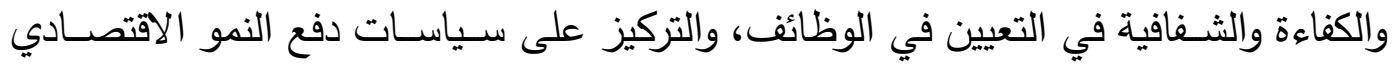

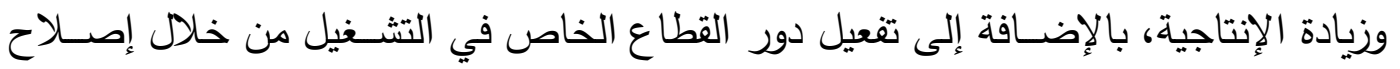

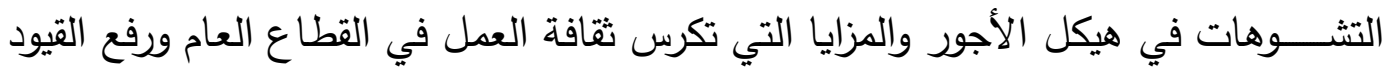

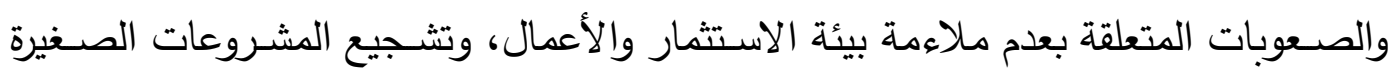

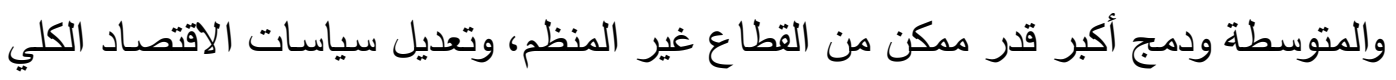

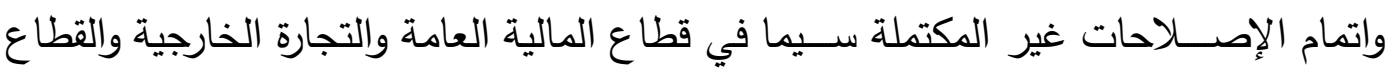

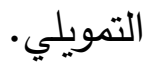

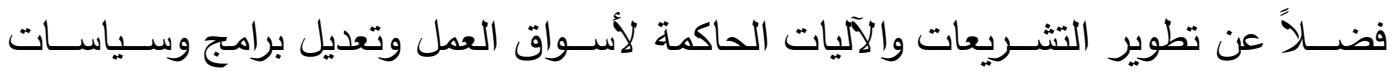

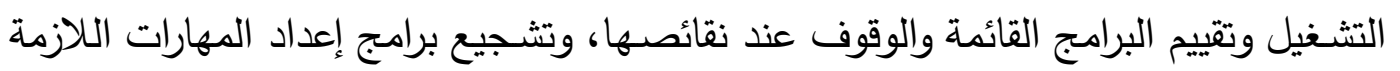

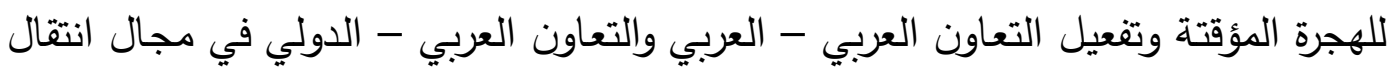

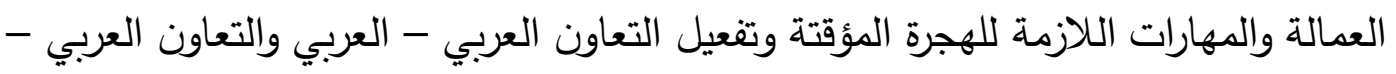

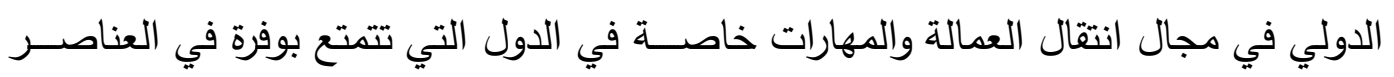

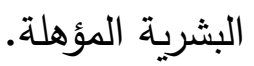

ثالثاً : تهيئة المناخ المناسـب لإعادة الإعمار وذلك من خلال البحث عن حلول ومعالجات سـريعة

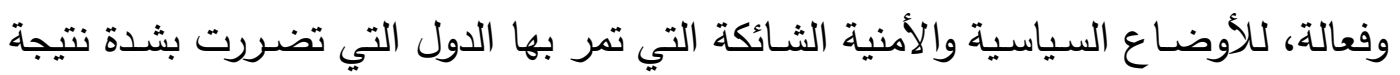

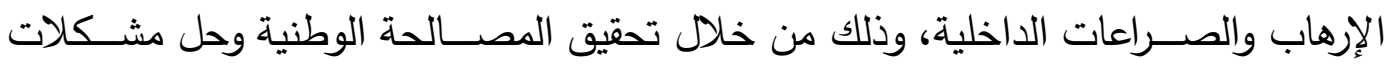

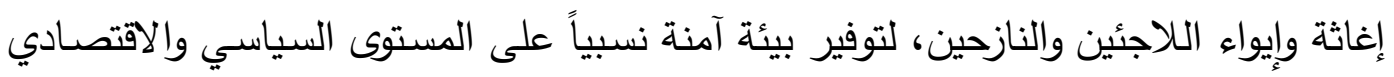

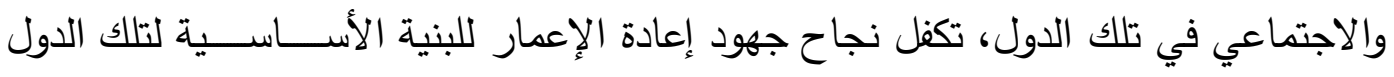
فضلاً عن تسهيل تتفيذ برامج إعادة التأهيل النفسي والبدني لمواطنيها ليتسنى تأهيلهم مهارياً

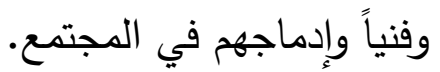
رابعاً: أهمية الاندماج في عصر الأتمتة الجديد لما يتطلبه من مهارات عالية للوظائف الجديدة التي

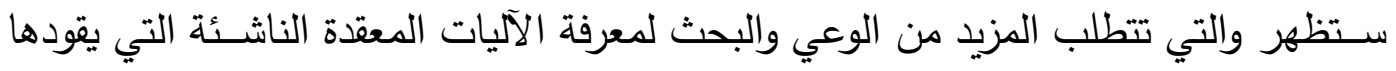
الذكاء الاصطناعي، بالإضـافة إلى أهمية تحديد الوظائف الوسيطة من خلال تداخل التفاعل 
بين الإنسـان والآلة في مختلف المجالات وذلك على النحو الذي يعظم الاسـتفادة من الأتمتة كمرك للإنتاجية والنمو الاقتصادي والوظائف المستقبلة. 


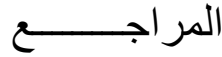

أولاً: المراجع باللغة العربية

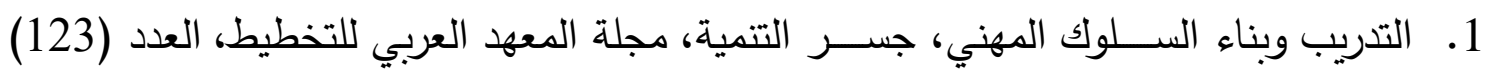
أبريل التبل 2015.

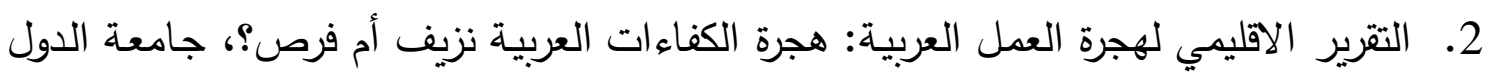

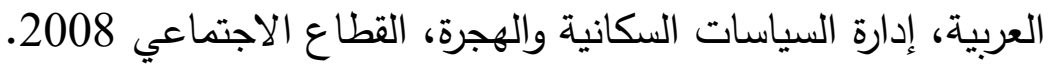

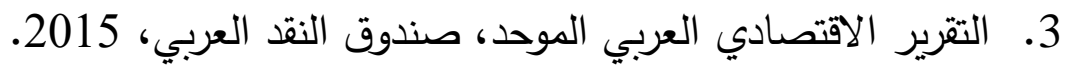

4. تقرير الأهداف الإنمائية للألفية، الأمم المتحدة، 2015.

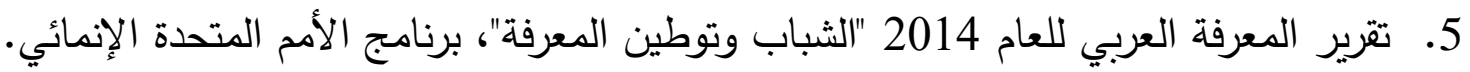

6. تقرير معهد ماكنزي العالمي حول مستقبل العمل، يناير 2017.

7. Chandran العالمية للحكومات، يناير 2018.

8. دراسة الحكومة الالكترونية 2014، الأمم المتحدة، إدارة الثؤون الاجتماعية والاقتصادية.

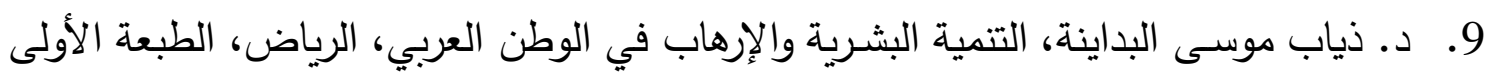
.2010

10. رأس المال غير المادي ودوره في التتمية الاقتصادية: حالة الدول العربية، جسر التتمية، مجلة

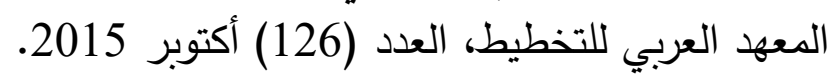

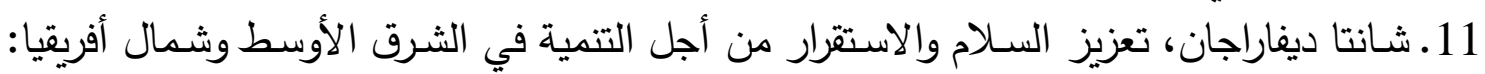

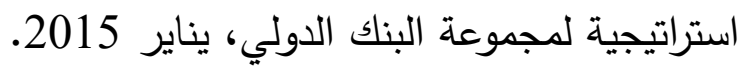

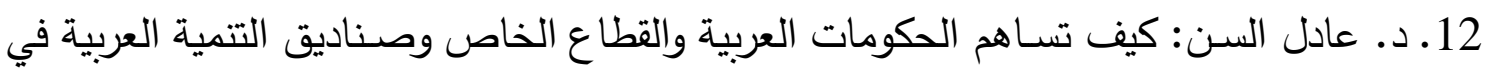

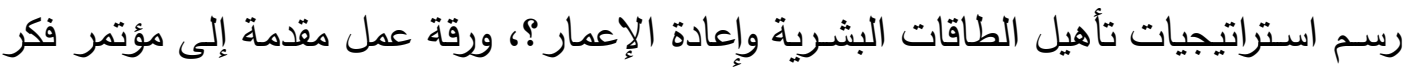

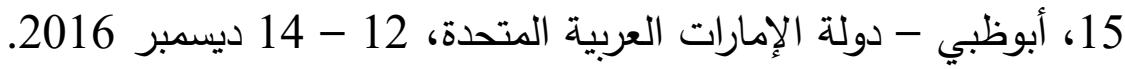

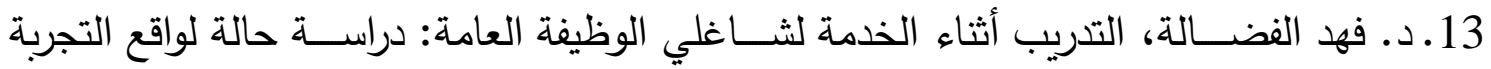
الكويتية، سلسلة دراسات تتموية، المعهد العربي للتخطيط، العدد (49) أكتوبر 2015.

ثانياً: مراجع باللغة الأجنبية

1. Doing Business 2016.

2. ILO: Global Employment Trends for Youth 2015.

3. ILO: World Employment Social Outlook 2016.

4. Social Progress Imperative: SPI 2016.

5. Transparency International: CPI Report 2015.

6. UNDP, HDR 2015. 
7. UNESCO: The Privatization of Education in Developing Countries. Evidence and Policy Implications.

8. UN: The Third Report on the Millennium Development Goals 2010 and the Impact of the Global Economic Crises.

9. World Bank, World Development Report 2016.

10.World Economic Forum: Global Competitiveness Index 2015. 